\title{
Ternary system Portland cement-calcium aluminate cement-calcium sulfate applied to self-leveling mortar: a literature review
}

\author{
A.C.A.Rego ${ }^{1,2}$, F.A.Cardoso ${ }^{2,3 *}$, R. G. Pileggi ${ }^{2,3}$ \\ ${ }^{1}$ Imerys - Refractory, Abrasives \& Construction, Mogi das Cruzes, SP, Brazil \\ ${ }^{2}$ University of São Paulo, Escola Politécnica, Department of Construction Engineering, \\ Av. Prof. Almeida Prado 83, 05508-070, S. Paulo, SP, Brazil \\ ${ }^{3}$ National Institute on Advanced Eco-efficient Cement-based Technologies, São Paulo, SP, Brazil
}

\begin{abstract}
The modernization of building systems is increasingly demanding products that improve efficiency during their processing. The development of self-leveling mortars for the regularization of flooring is a consequence of this evolution. The high contents of binder and water to obtain self-flowing property, plus the application of thin layers over large areas, make this type of mortar susceptible to high shrinkage levels. Thus, the ternary system Portland cement-calcium aluminate cement-calcium sulfate $\left(\mathrm{OPC}-\mathrm{CAC}-\mathrm{CaSO}{ }_{4}\right)$ is a viable solution for shrinkage compensation. The expansion mechanism based on ettringite formation aims to prevent the mortar from cracking. Considering its complexity and that international literature is still limited (while Brazilian is null), this article presents a literature review that covers diverse aspects related to the application of the system OPC-CAC-CaSO . The influence of raw materials and mix proportions on rheological behavior, reaction kinetics, development of strength, and length change are discussed. Keywords: ternary system, Portland cement, calcium aluminate cement, calcium sulfate, self-leveling mortar, shrinkage compensation, high-early strength.
\end{abstract}

\section{INTRODUCTION}

The modernization and industrialization of building systems are increasingly requiring products that speed up construction processes and boost productivity by reducing costs, raw materials transportation, and labor time during product application. The screed mortar method and its regularization are determining factors in the efficiency of the entire constructive process [1]. Traditionally, in Brazil, the semi-dry cementitious screed type is the most commonly used [2]. Its consistency requires highenergy mechanical compaction and can reach a productivity of $150 \mathrm{~m}^{2} /$ day [3]. However, as a consequence of rationalization demands in the constructive processes, the self-leveling mortar is requested and can increase potential productivity up to 2400 $\mathrm{m}^{2}$ /day by a worker [4], thus allowing substantial productivity and quality improvement mainly for large areas. This mortar is defined by its self-leveling property, flowing due to the effect of gravity without the need for vibration or compaction, which allows its application by a single operator in an ergonomically safe manner (and in most cases, the mortar is transported by pumping), replacing the traditional screed or regularizing the existing screed surface. It is used in garages, parking lots, industrial areas, shopping centers with heavy to moderate pedestrian traffic, or as a decorative floor for indoor and outdoor residential areas [1]. Fig. 1 shows images of both technologies, semi-dry cementitious screed and self-leveling mortar.

*fabio.cardoso@lme.pcc.usp.br

Dhttps://orcid.org/0000-0003-2642-0428

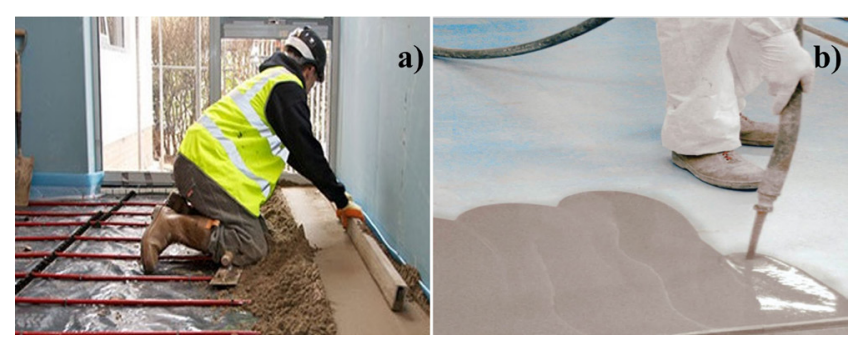

Figure 1: Images of traditional semi-dry cementitious screed (a) and self-leveling mortar (b) [5].

To achieve the desired fluidity, the cementitious selfleveling mortar requires a significant water amount. Even with the employment of dispersant additives, such as naphthalene sulfonate formaldehyde (SNFs), polycarboxylate (PC), or polycarboxylate ether (PCE) [6], and particle packing techniques, the water content can still reach values between $19 \%$ and $24 \%$ by dry mix weight, depending on type and function of the self-leveling product [7-10]. Therefore, the cementitious material is susceptible to drying shrinkage due to evaporation of free water or its absorption by the substrate, a situation that is maximized by the usual high area/volume ratio of this application of self-leveling mortars [11]. Shrinkage can cause cracking, which compromises material strength, aesthetics, and exposes the product and deeper layers to aggressive agents, consequently reducing the service life of the system [12]. Since dimensional stability is highly important for this type of application, several strategies are employed in this direction: Portland cement partial replacement by mineral additions such as secondary raw materials (SRM), cracking 
propagation control by the addition of polymer or steel fibers [13], shrinkage reducing admixtures (SRA) in order to decrease autogenous and drying shrinkage [14], or shrinkage compensation. Shrinkage compensation can be achieved by hydroxide-forming expander additives by lime $(\mathrm{CaO})$ or periclase $(\mathrm{MgO})$ hydration [15] (G type expander additive based on super calcined calcium oxide is the unique shrinkage compensator normalized in Brazil, according to ABNT NBR 11768:2019 standard [16]) or shrinkage compensating admixtures (SCA) produced by components rich in $\mathrm{CaO}, \mathrm{Al}_{2} \mathrm{O}_{3}$, and $\mathrm{SO}_{3}$ in pre-fixed proportion. SCAs are added to the mortar production and react with Portland cement to form ettringite $\left(\mathrm{CaO} \cdot \mathrm{Al}_{2} \mathrm{O}_{3} \cdot 3 \mathrm{CaSO}_{4} \cdot 32 \mathrm{H}_{2} \mathrm{O}\right)$, incorporating 32 water molecules in its structure, $46 \%$ by weight, and causing compensatory expansion by significantly increasing the volume of the paste during the hardening period right after the setting time [17]. Therefore, it makes the cementitious system an expansive cement [14].

A well-known expansive cement type is the ternary system OPC-CAC-CaSO ${ }_{4}$, composed of Portland cement (OPC), calcium aluminate cement (CAC), and anhydritetype calcium sulfate $\left(\mathrm{CaSO}_{4}\right)$. It is used in Portland cementrich self-leveling mortars to achieve properties such as dimensional stability through shrinkage compensation, acceleration of setting time, and increased strength in the first hours and over the hydration period. This system is a solution developed and implemented predominantly in foreign countries [14], while in Brazil, the use is still restricted, and the scientific literature scarce. Therefore, this article aims to bring together fundamental aspects of self-leveling mortars based on the ternary system OPCCAC-CaSO ${ }_{4}$, in order to improve the general knowledge of the advantages and difficulties during its formulation and application. The intention is to highlight which raw materials should be used and how the dosages between components affect the different aspects of the product, such as rheological behavior, reaction kinetics, length change, and development of strength. Additionally, comparative analyses with other solutions for dimensional stability are also discussed.

\section{SELF-LEVELING MORTAR}

Self-leveling mortar applied in industrial, commercial, or residential floors is mainly defined by the easy filling of large areas with small thickness over a short period. However, in addition to adequate performance in the fresh state, the hardened mortar must also meet the requirements of strength and surface properties, i.e., an abrasion-resistant surface without cracks, undulations, or stains. Fig. 2 shows two different examples of self-leveling mortar applications, industrial and decorative floors. The application process usually involves 4 to 5 workers per work front. It includes steps of base preparation with sealing layer, application, and finishing [18]. Thus, both combinations of raw materials and application process must be adequate to achieve the required properties and avoid pathological manifestations such as segregation, bleeding, lack of adhesion, uneven surface, high permeability, and cracking.

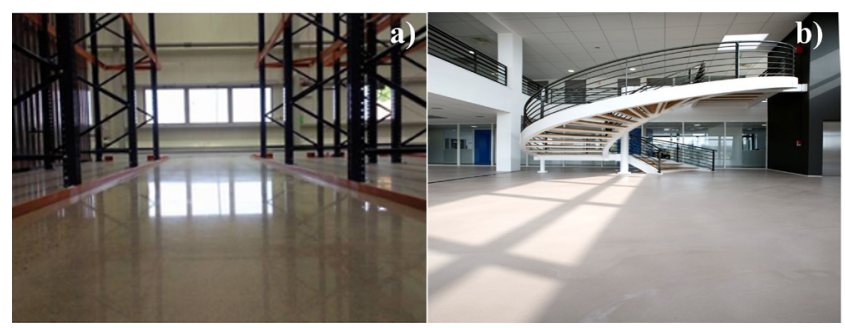

Figure 2: Images of examples of self-leveling mortar applications: a) industrial floor; and b) decorative floor [5].

Average properties required by self-leveling mortars, such as thickness range, self-flowing time, time to release pedestrian traffic, self-drying time to allow coating, strength development, and maximum length change, vary according to the specifications of each manufacturer. Therefore, in order to have a standardized performance, technical standards are required to regulate the product properties and indicate which test methods are important for the self-leveling mortar evaluation and application. In the USA, ASTM C1708/C1708M-19 "Standard test methods for self-leveling mortars containing hydraulic cements" describes which properties should be controlled and the test methods to be used in order to evaluate flowability, workability time, and physical properties such as setting time, compressive and flexural strength, and length change. Therefore, as there is no standardization for this application in Brazil, ASTM C1708 should be considered the basis for property evaluation. It separates hydraulic binder-based self-leveling mortars into two types depending on each application: self-leveling underlayment (SLU) that receives top coatings such as ceramic tiles, laminate, vinyl, textiles, wood, resin-coated, or raised flooring [19]; and self-leveling overlayment (SLO), which is used as a wear surface, without the need of a protective layer. Both types are used for surface regularization with thicknesses of 1 to $10 \mathrm{~mm}$ [20]. However, it is also possible that the semi-dry cementitious screed type subfloor is replaced by a self-leveling mortar, described as self-leveling screed (SLS), with a thickness range of 20 to $70 \mathrm{~mm}$ [21]. Self-leveling compound (SLC) is a term also found in the literature, and it refers to a generic name for all types previously described. Fig. 3 shows a system that presents SLS and SLU as components. Regardless of

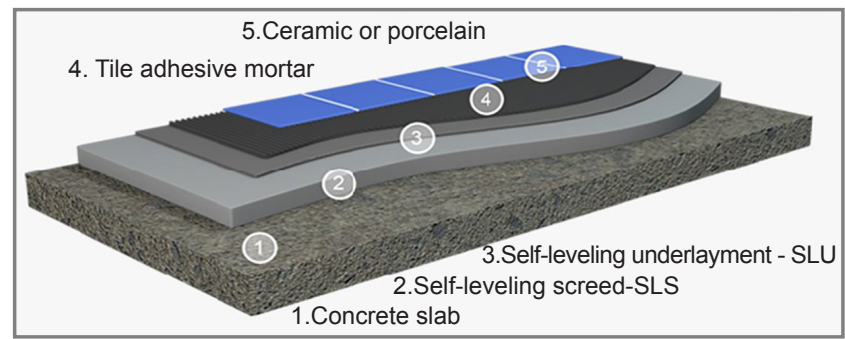

Figure 3: Schematic of a floor system composed of concrete slab, self-leveling screed (SLS), self-leveling underlayment (SLU), and tile adhesive mortar with ceramic or porcelain [5]. 
the self-leveling type, dimensional variation is important and should be controlled since shrinkage in this type of cementitious product can compromise its performance. Thorough understanding of this phenomenon, the seek for efficient solutions is an important step to prevent problems in the short or long term.

Shrinkage of cementitious self-leveling mortars: mortars are concentrated cementitious suspensions composed of fine aggregates, reactive fines, water, and, in certain cases, inert fillers, chemical additives, and fibers [22]. Thus, compared to conventional mortars, the self-leveling type is highlighted in this context by incorporating dispersant additives and high contents of fines and water in its composition in order to reduce yield stress and viscosity of the material. Thus, the application of self-leveling mortars should be performed by gravity in a simple way but also be cohesive and homogeneous so as to maintain a moderate product viscosity, ensure a leveled surface and avoid bleeding and segregation [1]. Regardless of the mortar type, cement suspensions are subjected to the phenomenon of shrinkage on a larger or smaller scale depending on their fundamental characteristics. The self-leveling mortar is a complex product mainly due to its high demand for hydraulic binders and water and its geometry with considerable area/volume ratio when applied, which intensifies drying and shrinkage mainly in the surface in contact with air and can induce the appearance of curling and cracks (Fig. 4).

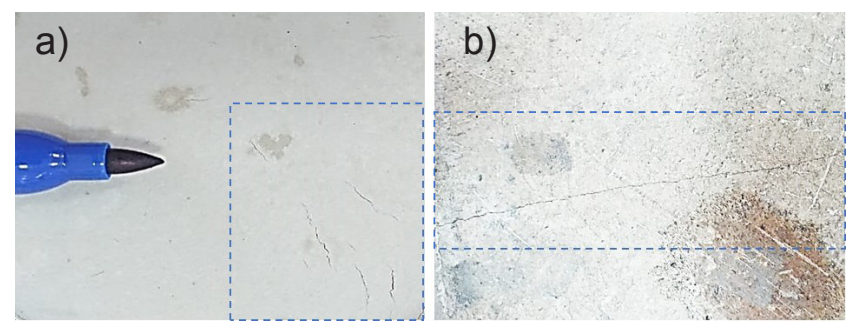

Figure 4: Images of examples of cracking found on self-leveling mortars.

There are several types of shrinkage that can result in dimensional variation of cementitious systems. Each type should be analyzed separately in order to identify the reasons for the phenomenon and which techniques can be used to avoid it. Fig. 5 shows the types of shrinkage that are likely to occur in the fresh or hardened state and how their motivating mechanisms are interconnected. Despite the various types that can occur, the drying, the autogenous, and the plastic shrinkage are the main causes of cracking of cementitious systems such as self-leveling mortars [12]. Therefore, due to self-leveling characteristics, the types of shrinkage resulting from the properties and actions required in the formulation and application of this product can be summarized in Fig. 6 .

Shrinkage compensation by ettringite formation: due to the severe shrinkage that self-leveling cementitious systems are subjected to, a compensation mechanism by the formation of the ettringite chemical compound $(\mathrm{CaO}$. $\left.\mathrm{Al}_{2} \mathrm{O}_{3} \cdot 3 \mathrm{CaSO}_{4} \cdot 32 \mathrm{H}_{2} \mathrm{O}\right)$ is a solution applied to achieve

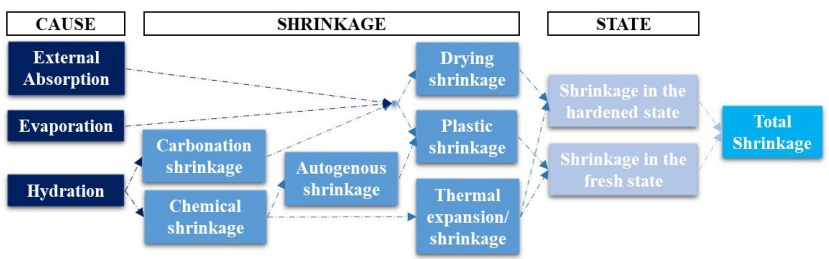

Figure 5: Scheme of interconnection between cause, type, and state for the shrinkage to which cementitious systems are subjected (adapted from [23]).

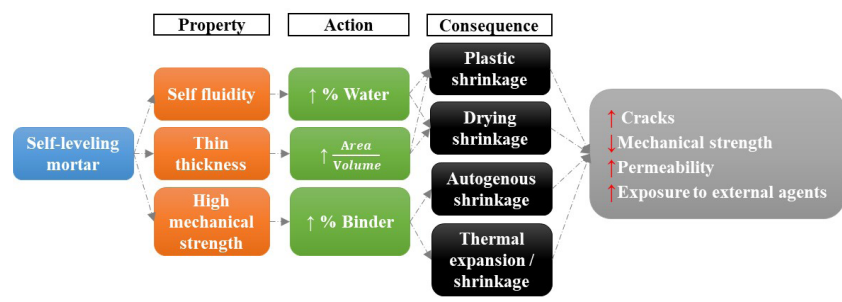

Figure 6: Diagram of properties, actions needed to achieve them, and consequences that can cause pathological manifestations in self-leveling mortars.

dimensional stability. Its formation must be controlled (moment and quantity) through the hydration reaction of the hydraulic binders rich in $\mathrm{CaO}, \mathrm{Al}_{2} \mathrm{O}_{3}$, and $\mathrm{SO}_{3}$. Comparatively, length changes over the first $24 \mathrm{~h}$ and over the hydration period with and without shrinkage compensation are observed in Fig. 7. The groups formed by the components are classified according to their expanding agents. ASTM C845:2018 defines three types of expansive hydraulic cements, considered as slow expansion (expansive reactions from 1 to 7 days at water conditions) and mainly used for concrete applications [26, 27]: i) K-type: Portland cement blended with anhydrous calcium sulfoaluminate $\left(4 \mathrm{CaO} \cdot 3 \mathrm{Al}_{2} \mathrm{O}_{3} \cdot \mathrm{SO}_{3}\right)$, gypsum $\left(\mathrm{CaSO}_{4} \cdot 2 \mathrm{H}_{2} \mathrm{O}\right)$ and free lime $(\mathrm{CaO})$, which reaction stoichiometry is given by Eq. A; ii) S-type: Portland cement with a high amount of tricalcium aluminate $\left(\mathrm{C}_{3} \mathrm{~A}\right)$ and gypsum $\left(\mathrm{CaSO}_{4} \cdot 2 \mathrm{H}_{2} \mathrm{O}\right)$, which reaction stoichiometry is given by Eq. $\mathrm{B}$; and iii) M-type: Portland cement blended with calcium aluminate $\left(\mathrm{CaAl}_{2} \mathrm{O}_{4}\right)$ and gypsum $\left(\mathrm{CaSO}_{4} \cdot 2 \mathrm{H}_{2} \mathrm{O}\right)$, which reaction stoichiometry is given by Eq. C:

$$
\begin{aligned}
& \mathrm{C}_{4} \mathrm{~A}_{3} \overline{\mathrm{S}}+8 \mathrm{C} \overline{\mathrm{S}} \mathrm{H}_{2}+6 \mathrm{CH}+74 \mathrm{H} \rightarrow 3 \mathrm{C}_{6} \mathrm{AS}_{3} \mathrm{H}_{32} \\
& \mathrm{C}_{3} \mathrm{~A}+3 \mathrm{C} \overline{\mathrm{S}} \mathrm{H}_{2}+26 \mathrm{H} \rightarrow \mathrm{C}_{6} \mathrm{~A}_{3} \mathrm{H}_{32} \\
& \mathrm{CA}+3 \mathrm{C} \overline{\mathrm{S}} \mathrm{H}_{2}+2 \mathrm{CH}+24 \mathrm{H} \rightarrow \mathrm{C}_{6} \mathrm{AS}_{3} \mathrm{H}_{32}
\end{aligned}
$$

where $\mathrm{C}=\mathrm{CaO}, \mathrm{A}=\mathrm{Al}_{2} \mathrm{O}_{3}, \overline{\mathrm{S}}=\mathrm{SO}_{3}, \mathrm{H}=\mathrm{H}_{2} \mathrm{O}, \mathrm{C}_{4} \mathrm{~A}_{3} \overline{\mathrm{S}}=4 \mathrm{CaO} .3 \mathrm{Al}_{2} \mathrm{O}_{3}$. $\mathrm{SO}_{3}$ - anhydrous calcium sulfoaluminate (CSA, ye'elimite), $\mathrm{CS} \mathrm{H}_{2}=\mathrm{CaSO}_{4} \cdot 2 \mathrm{H}_{2} \mathrm{O}-$ gypsum or dihydrate, $\mathrm{CH}=\mathrm{Ca}(\mathrm{OH})_{2}$ calcium hydroxide, $\mathrm{CA}=\mathrm{CaAl}_{2} \mathrm{O}_{4}$ - calcium aluminate, and $\mathrm{C}_{3} \mathrm{~A}=\mathrm{Ca}_{3} \mathrm{Al}_{2} \mathrm{O}_{6}$ - tricalcium aluminate.

The CSA presented in K-type can be added to Portland cement-rich blends, reducing setting time but non promoting high initial strength [28]. However, the increase of initial 


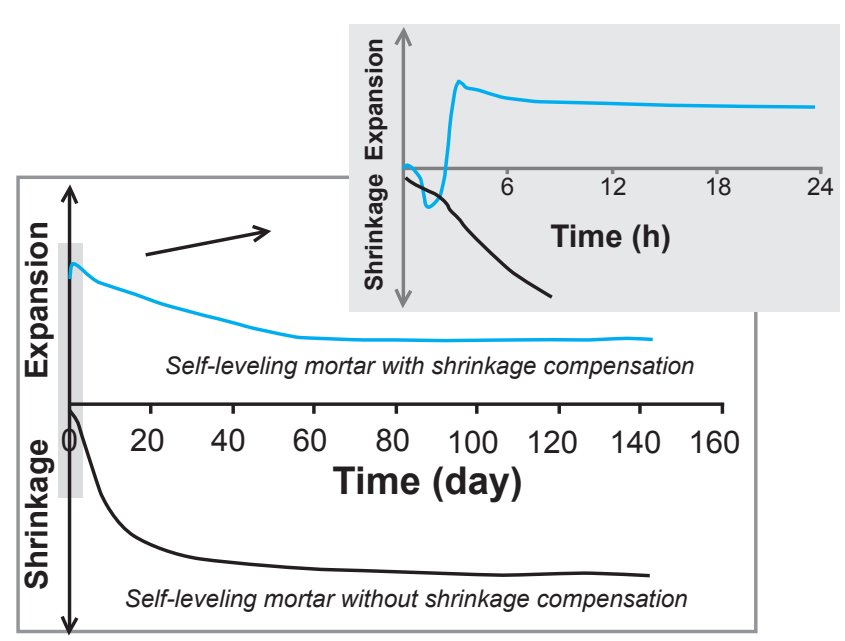

Figure 7: Schematic of length changes of self-leveling cementitious mortars with and without shrinkage compensation by fast set and expansion at air conditions up to 160 days (adapted from [24, 25]).

strength can indeed be achieved in combinations of Portland and CSA, but only when CSA rich blends are prepared [29, 30]. Although $\mathrm{K}$-type is required for dimensional stability, its use in Portland cement-rich formulations does not guarantee considerable development of ettringite hydrate at early hours, which is an important requirement for self-leveling mortars. S-type expansive cement consists of a Portland cement produced with a high amount of $\mathrm{C}_{3} \mathrm{~A}$ and calcium sulfate when compared to ordinary Portland cement [27]. Like the others, M-type expansive cement is adequate mainly for concrete applications. As the concretes need to be cured for 7 days in humid conditions, the slow expansion can occur efficiently during this period, and the expansive component does not affect other important properties as setting time and strength development. However, for self-leveling mortars that are usually more exposed to variable and often unfavorable ambient curing conditions (temperature, wind, and humidity), the ternary system OPC-CAC-CaSO ${ }_{4}$ is more indicated due to its fast ettringite formation. Besides the shrinkage compensation benefits, this system also reduces setting time and promotes strength in a few hours, hence allowing the faster release of the area for pedestrian traffic and overall usage of the area.

\section{TERNARY SYSTEM OPC-CAC-CaSO}

Although the ternary system OPC-CAC-CaSO ${ }_{4}$ is used in various types of cementitious applications, its reaction mechanism, and its consequences are still considered poorly understood by many authors [31-37]. However, the consequences of its use regarding shrinkage compensation, setting time acceleration, strength development, and selfdrying are well known, and these are important properties for situations that require the quick release of the work as for self-leveling mortars [38]. In Brazil, because this system does not have a standard, its advantages are not yet fully disseminated in the academic and industrial communities, where its use and knowledge are considered scarce, hindering correct control during formulation and application. However, this OPC-rich system was chosen to be studied since Portland cement is the main cementitious system, which reflects in the low price compared to the other binders as calcium aluminates. Nevertheless, its isolated use does not provide the requested properties for high-quality self-leveling mortars. Therefore, calcium aluminate and calcium sulfate are used in order to guarantee performance, and the corresponding rates are already known [39]. The usual proportions are highlighted in Fig. 8.

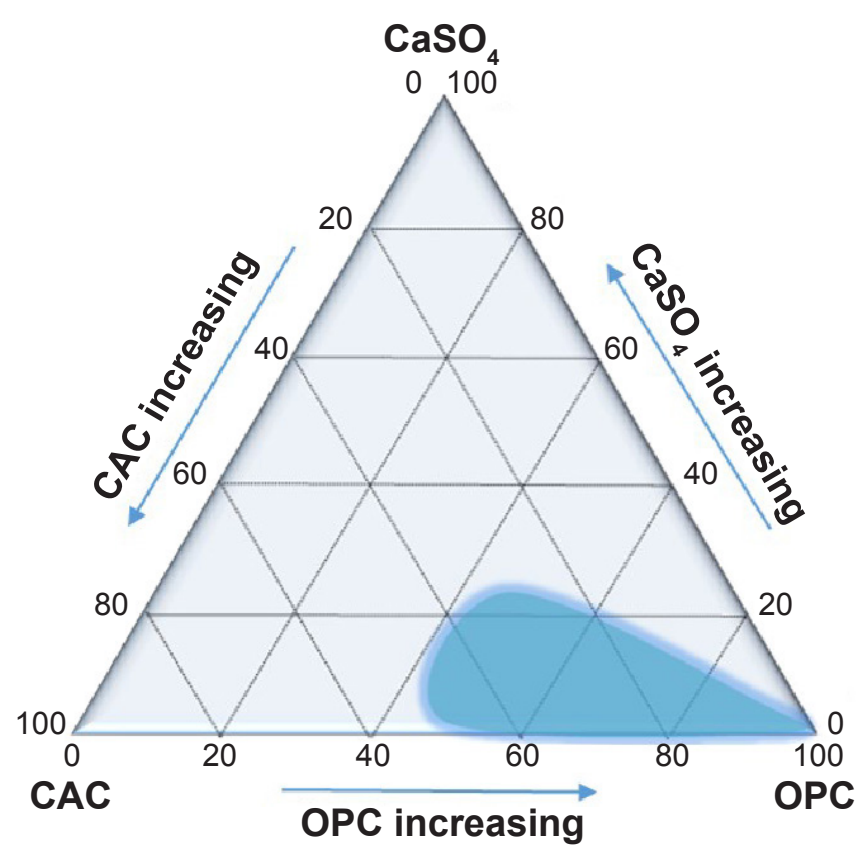

Figure 8: Ternary system OPC-CAC-CaSO 4 with a highlighted area for Portland cement rich systems (adapted from [5, 39]).

Raw materials of ternary system $\mathrm{OPC}-\mathrm{CAC}-\mathrm{CaSO}_{4}$ : due to the several possibilities of each ternary system component, Portland cements, calcium aluminates, and calcium sulfates, the choice of each component is essential.

Portland cement: this product is the most used in construction worldwide, being the most consumed material after water [40]. Its application is widely disseminated, both in the structural part through concrete for slabs, pillars, beams, and walls and in mortars for general coating. Its common composition is mainly defined by clinker and calcium sulfate. Clinker is formed by mixing and firing limestone and clay in rotary kilns at temperatures up to $1450{ }^{\circ} \mathrm{C}$, resulting mainly in the phases: i) alite $\left(\mathrm{C}_{3} \mathrm{~S}\right): 50 \%$ to $70 \%$ by mass, which determines the initial hydration through setting time and the strength development by precipitation of C-S-H calcium silicate gel and portlandite [31]; ii) tricalcium aluminate $\left(\mathrm{C}_{3} \mathrm{~A}\right): 7 \%$ to $11 \%$ by mass [41], extremely reactive phase that affects hydration kinetics at an early age and reacts according to the presence or absence of calcium sulfate and $\mathrm{Ca}(\mathrm{OH})_{2}[42]$; iii) belite $\left(\mathrm{C}_{2} \mathrm{~S}\right)$ : reacts after 7 to 10 days of the mixture with water [43]; and iv) calcium ferroaluminate $\left(\mathrm{C}_{4} \mathrm{AF}\right): 7 \%$ to $13 \%$ by mass [41], reacts slowly but without calcium sulfate can react $40 \%$ after 1 day of hydration [43]. In 
addition to clinker, there is calcium sulfate $\left(\mathrm{CaSO}_{4} \cdot \mathrm{xH}_{2} \mathrm{O}, \mathrm{x}=\right.$ $0,1 / 2$, or 2 ), which controls the $\mathrm{C}_{3} \mathrm{~A}$ hydration by forming an ettringite hydrate barrier surrounding it (known as inhibiting layer theory), which avoids its instant setting and gives an extended workable time for processing and application of the material. Recently, the geochemistry dissolution theory has also been considered by many authors as an evolution for the interpretation of Portland cement hydration; however, it is still not totally established $[44,45]$. The optimum amount of calcium sulfate ranges from $3 \%$ to $5 \%$ by mass $[41,46$, 47]. Above this value, the setting time remains practically constant, causing overdosage of the material and strength decrease [41]. Besides these components, mineral additions may be incorporated into Portland manufacturing in order to improve its durability, strength, and workability properties, as well as reducing energy costs and $\mathrm{CO}_{2}$ footprint. These additions can be blast furnace slag, pozzolanic materials, and calcium carbonate [48].

Portland cement hydration reactions are exothermic as well as calcium aluminate cement. The resulting heat curve scheme of these reactions for both cements and their specifications are shown in Fig. 9. The choice of the Portland cement type to be used in self-leveling mortars of the ternary system OPC-CAC-CaSO ${ }_{4}$ takes into account important factors such as low yield stress and moderate viscosity in the fresh state, rapid setting, and early strength. In addition, as the self-leveling mortar system is extremely complex, the variables should be reduced as much as possible to avoid unexpected interactions between the components. Therefore, in Brazil, CP V-ARI (high-early strength, nonsulfate resistant) is the most suitable Portland cement type for this application. Due to its high specific surface area, this cement already presents reduced setting time and fast strength development compared to other Portland cements. In addition, its low clinker substitution by additions according to ABNT NBR 16697:2018 standard (0-10\% of calcium carbonate by mass) simplifies the binder dosage.

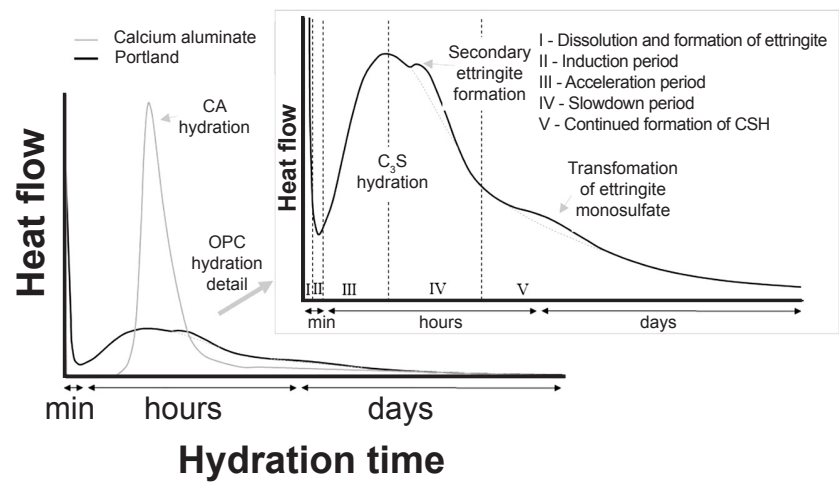

Figure 9: Scheme of heat flow evolution during Portland cement and calcium aluminate cement hydration with highlighted reactions (adapted from [31, 49]).

Calcium aluminate cement (CAC): is the second component in the quantity of the ternary system OPCCAC-CaSO ${ }_{4}$. It is designed to be more resistant than Portland cement to sulfate attacks but is also used due to its properties as high initial strength and high acid neutralization [50]. Currently, this binder can be imported from countries such as Turkey, Spain, Netherlands, United States, France, and China. Its use involves applications such as refractory castables, environments with a harsh chemical attack or abrasive, and nonstructural elements such as finishing coatings [17]. From the building point of view, the greatest demand is for products dedicated to floor elements (screed, self-leveling, adhesive mortars for ceramics and natural stones, tile grouts), wall preparation, and concrete repair (quick repair, waterproofing, non-shrink grout). For such applications, CAC can be combined with Portland and calcium sulfate depending on the property required: i) binary OPC-CAC: Portland cement setting time acceleration by addition of calcium aluminate; ii) ternary CAC-OPC-CaSO ${ }_{4} \cdot \frac{1}{2} \mathrm{H}_{2} \mathrm{O}$ : calcium aluminate rich system with the addition of Portland cement and calcium sulfate as hemihydrate, used for dimensional stability, fast strength development, fast self-drying, and efflorescence inhibition; and iii) binary CAC-CaSO ${ }_{4} \cdot 1 \frac{1}{2} \mathrm{H}_{2} \mathrm{O}$ : same advantages as above but more robust due to the absence of Portland cement. In addition to the above applications, recent researches have shown that calcium aluminate represents a solution for 3D concrete printing (3DCP), where the intrinsic reactivity can be altered using the Portland plus calcium aluminate binary system [51].

CAC differs from Portland cement mainly due to the high amount of alumina $\left(\mathrm{Al}_{2} \mathrm{O}_{3}\right)$ in its chemical composition, which can range from $40 \%$ to $80 \%$. The highest alumina grades $(70-80 \%)$ are produced from pure raw materials, metallurgical alumina, and lime in rotary kilns similar to those used in the manufacture of Portland cement. Low alumina grades (40-60\%) are manufactured by the complete fusion of bauxite (its type and iron oxide content determine the color of the material, which can be gray or black) and limestone in a 'reverberatory' furnace [38]. Calcium aluminate types are mainly based on the $\mathrm{CA}_{2}, \mathrm{CA}$, and $\mathrm{C}_{12} \mathrm{~A}_{7}$ mineralogical components that differ in their reactivity. Thus, the lowest the $\mathrm{Al}_{2} \mathrm{O}_{3} / \mathrm{CaO}$ ratio, the greater the interaction with water and the strength. In contrast, the refractoriness is higher as the richer in alumina the component is, i.e., $\mathrm{C}_{12} \mathrm{~A}_{7}$ $<\mathrm{CA}<\mathrm{CA}_{2}$ [52]. Thus, high alumina calcium aluminates, and consequently $\mathrm{CA}_{2}$ (decomposition temperature: 1750$\left.1765^{\circ} \mathrm{C}[53,54]\right)$, are mostly used in refractory applications, whereas in building applications, where water reactivity and strength are determining factors, the cements with lower $\mathrm{Al}_{2} \mathrm{O}_{3} / \mathrm{CaO}$ ratio should be prioritized. Another determining factor is the iron content, as the higher this value, the lower its hydraulic reactivity, and the phase containing iron is strongly delayed with the presence of sulfate anions [55]. Table I shows the chemical and mineralogical compositions found in the literature and product data sheets of the main calcium aluminates on the market compared to OPC. Calcium aluminates have no significant $\mathrm{SO}_{3}$ content compared to Portland cement, which receives gypsum in its manufacturing for setting time control.

The use of only calcium aluminate as a binder in 
Table I - Chemical and mineralogical composition of Portland cement and calcium aluminate types with alumina content of $40 \%, 50 \%, 60 \%, 70 \%$, and $80 \%$ and $\mathrm{C}_{12} \mathrm{~A}_{7}$-rich clinker $[38,56,57]$.

\begin{tabular}{ccccccc}
\hline \multirow{2}{*}{ Binder material } & \multicolumn{3}{c}{ Chemical composition } & \multicolumn{2}{c}{ Mineralogical composition } \\
& $\mathrm{Al}_{2} \mathrm{O}_{3}$ & $\mathrm{CaO}$ & $\mathrm{Fe}_{2} \mathrm{O}_{3}$ & $\mathrm{SiO}_{2}$ & Main phases & Secondary phases \\
\hline OPC & - & +++ & - & + & $\mathrm{C}_{3} \mathrm{~S}, \mathrm{C}_{2} \mathrm{~S}$ & $\mathrm{C}_{3} \mathrm{~A}, \mathrm{C}_{4} \mathrm{AF}, \mathrm{C}$ \\
$40 \%$ alumina & ++ & ++ & + & - & $\mathrm{CA}, \mathrm{C}_{4} \mathrm{AF}$ & $\mathrm{C}_{12} \mathrm{~A}_{7}, \mathrm{C}_{2} \mathrm{~S}$ \\
$50 \%$ alumina & +++ & ++ & - & - & $\mathrm{CA}$ & $\mathrm{C}_{2} \mathrm{AS}$ \\
$60 \%$ alumina & +++ & ++ & - & - & $\mathrm{CA}$ & $\mathrm{CA}_{2}, \mathrm{C}_{2} \mathrm{AS}$ \\
$70 \%$ alumina & ++++ & + & - & - & $\mathrm{CA}_{2} \mathrm{CA}_{2}$ & $\alpha \mathrm{A}$ \\
$80 \%$ alumina & ++++ & + & - & - & $\mathrm{CA}_{2} \mathrm{CA}_{2}, \alpha \mathrm{A}$ & - \\
$\mathrm{C}_{12} \mathrm{~A}_{7}$ rich clinker & ++ & +++ & - & - & $\mathrm{C}_{12} \mathrm{~A}_{7}, \mathrm{C}_{4} \mathrm{AF}$ & $\mathrm{C}_{2} \mathrm{~S}, \mathrm{CA}$ \\
\hline
\end{tabular}

+ indicates intensity in dosage; - present, but not significant.

applications that require stable strength over the lifetime demands high control of water dosage, temperature, and humidity. This is important due to the conversion of the less stable hexagonal calcium aluminate hydrate $\left(\mathrm{CAH}_{10}\right)$ to stable cubic tricalcium aluminate hydrate $\left(\mathrm{C}_{3} \mathrm{AH}_{6}\right)$, hydrated alumina $\left(\mathrm{AH}_{3}\right)$, and water. This conversion occurs after an extended period of time and may cause a reduction of up to $53 \%$ in the volume of hydrated material, thereby increasing porosity and consequently reducing the strength [58]. In addition to the crystalline calcium aluminate phases, there is currently also the amorphous calcium aluminate, which the process consists of cooling after melting in an electric furnace. Its composition follows the ratio $12: 7$ of $\mathrm{CaO}: \mathrm{Al}_{2} \mathrm{O}_{3}$ and has a much higher hydration rate than crystalline calcium aluminate; it is also used in mortars that require fast hardening and is based on the ternary system OPC$\mathrm{CAC}^{-\mathrm{CaSO}_{4}}[59,60]$. The Brazilian standard that describes CAC types is ABNT NBR 13847:2012 "Aluminous cement for use in refractory materials". In Europe, the standard that specifies the material is EN 14647:2005 "Calcium aluminate cement: composition, specifications and conformity criteria". For ASTM standards, the calcium aluminates are included in groups such as ASTM C1600/ C1600M-18 "Standard specification for rapid hardening hydraulic cement" and ASTM C845/C845M-18 "Standard specification for expansive hydraulic cement".

Calcium sulfates: calcium sulfate is present in the ternary system OPC-CAC-CaSO ${ }_{4}$ in two ways: the first originating from Portland cement and the second as the third component added to the system. This material is commonly known as plaster and can be applied in building applications as masonry coatings, blocks, ceiling panels, partitions, and selfleveling. Regarding its source, calcium sulfate is produced from natural sources such as gypsum calcination, or artificial (known as chemical plaster) as a waste from the fertilizer industry such as hydrofluoric acid and phosphoric acid [61, 62]. Brazilian reserves of gypsum are mainly located in Pará, Bahia, and Pernambuco States, with $96.9 \%$ of the total of the country. Gypsum has between $90 \%$ and $95 \%$ dihydrate concentration, impurities rarely exceeding $0.5 \%$. It is found in mineral deposits and can be used by grinding natural or calcined material to form hemihydrate or anhydrite when the technical specifications are most demanding [63]. In the South and Southeast regions of Brazil, the gypsum used is mainly phosphogypsum, a residue from the phosphate fertilizer industry [63]. In Brazil, 5.6 million tons of this material are generated annually [64].

Gypsum can be composed of different phases according to the amount of combined water and calcination temperature: dihydrate $\left(\mathrm{CaSO}_{4} \cdot 2 \mathrm{H}_{2} \mathrm{O}\right)$, natural form; $\alpha$ or $\beta$ hemihydrate $\left(\mathrm{CaSO}_{4} \cdot \frac{1}{2} \mathrm{H}_{2} \mathrm{O}\right), 140-160^{\circ} \mathrm{C}$; anhydrite $\mathrm{III}\left(\mathrm{CaSO}_{4}\right), 160-190$ ${ }^{\circ} \mathrm{C}$; anhydrite II, $250{ }^{\circ} \mathrm{C}$; and anhydrite I, $1200{ }^{\circ} \mathrm{C}$ [62]. In addition, solubility also varies with the selected type and solution temperature, as shown in Fig. 10, for a range of 0 to $60^{\circ} \mathrm{C}$. For the usual temperature range of application, the solubility of hemihydrate is much greater than the solubility values of anhydrite and dihydrate, which directly influences the choice for use in the ternary system, as discussed below. The main type of calcium sulfate used in plaster coating components is hemihydrate because it quickly turns into

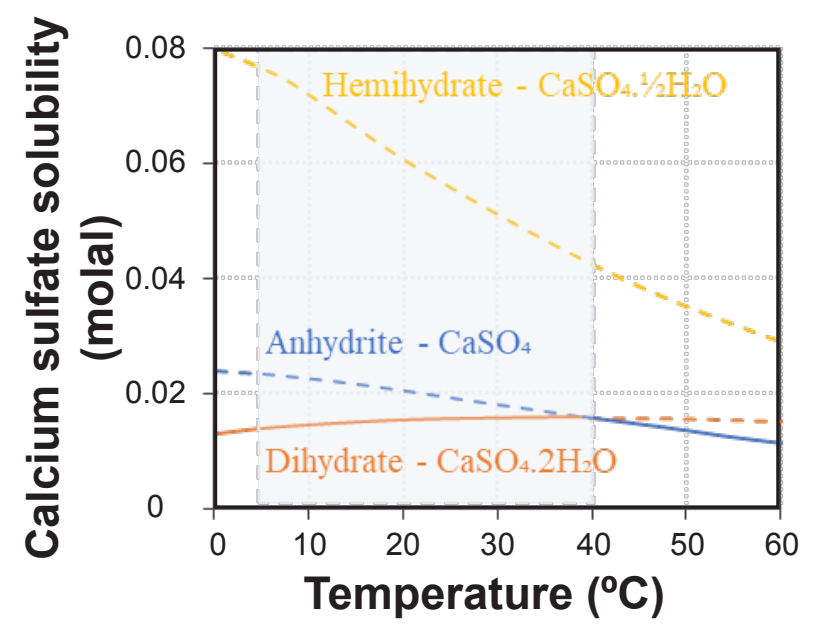

Figure 10: Phase diagram of calcium sulfate phases in water modeled using the mixed solvent electrolyte (MSE) design. The solid and dotted curves indicate the stable and metastable phases for each temperature, respectively. The highlighted area is the room temperature where the material usually is applied, 5 to $40{ }^{\circ} \mathrm{C}$ (adapted from [65]). 
dihydrate after mixing with water, generating volume increase, and linear expansion that can reach $0.2 \%$. This property practically prevents cracking in coatings because all mold voids are filled by the material, which explains its use in finishing components [62]. However, this property becomes a limitation when used in the ternary OPC-CAC-CaSO system. The expansion resulted from this high solubility of the hemihydrate can be exacerbated and difficult to control, which makes dimensional stability impossible and can cause cracks. Therefore, the most suitable type to be employed in the OPC-CAC-CaSO ${ }_{4}$ system is anhydrite, as explained in the following topics.

Dosage and materials properties: first of all, it is important to emphasize that the self-leveling mortar performance does not depend solely on the proportion between the components of the ternary OPC-CAC-CaSO ${ }_{4}$. Being a remarkable complexity cementitious system, the following trends are only a guide to how properties may vary. Therefore, it is important to be aware that, given a formulation prepared with defined raw materials, when reproducing it with materials of different origins, the results may be totally different, hence requiring re-dosing. Selfleveling performance varies from each application type and manufacturer product datasheet, although some articles can generalize and bring some usual values observed in Brazil [4]. Table II shows the ranges of materials dosage obtained through literature research [7-9]. The proportions between the components of the ternary system OPC-CAC-CaSO should be limited to the amount of binders and vary as per the demand for properties that are exemplified in the following topics. Even though dimensional stability is one of the main aspects related to the use of the ternary system in self-leveling mortars, it is important to understand reaction kinetics and how dosage affects rheological behavior and strength development. Only for illustration, Table II shows values that can be used in a self-leveling mortar formulation, including binders, filler, sand, water, and admixtures. This last item refers to admixtures incorporated into the product in order to improve the properties in the fresh and hardened states as well as to regulate setting time. The admixtures employed may include dispersants, viscosity modifiers, dispersible polymer powder, defoamer, setting time accelerators and retarders, and shrinkage reducers. The content of each specific admixture is hard to estimate due to the wide variety of types.

Table II - Typical self-leveling mortar formulation with common dosage ranges in $\mathrm{w} / \mathrm{w} \%$ (based on [7-9]).

\begin{tabular}{ccccc}
\hline Binders & Sand & Filler & Admixtures & Water/dry mix \\
\hline $30-40$ & $36-44$ & $13-28$ & $\sim 1-4$ & $19-24$ \\
\hline
\end{tabular}

Reaction kinetics: the reaction kinetics that promotes the setting time acceleration, and the initial strength is mainly affected by the OPC/CAC ratio. In Fig. 11, as the replacement of OPC by CAC increases, the setting time decreases until the $40-80 \%$ range is reached, in which reaction can be almost instantaneous. This curve is commonly known as ' $U$ curve'. The hydration mechanism that ensures the acceleration of the Portland cement is a consequence of the reaction between aluminum cations $\mathrm{Al}^{3+}$ of $\mathrm{CAC}$ dissolved with the sulfate anions $\mathrm{SO}_{4}^{2-}$ of gypsum in OPC. It, therefore, prevents the reaction of these sulfate anions with $\mathrm{C}_{3} \mathrm{~A}$, and the barrier that would form around $\mathrm{C}_{3} \mathrm{~A}$ grains is not developed, releasing its reaction with water and originating a high amount of heat from ettringite formation, which then decreases setting time $[32,35,67]$. In this system, the setting time is highly dependent on CAC and OPC types, influencing the CAC quantity needed to provide the requested setting time. This is mainly due to the nature of calcium sulfate present in OPC. The higher the solubility of calcium sulfate, such as hemihydrate, the greater the amount of CAC required to reach the acceleration level. Therefore, CAC dosage should be adjusted for each Portland cement [17].

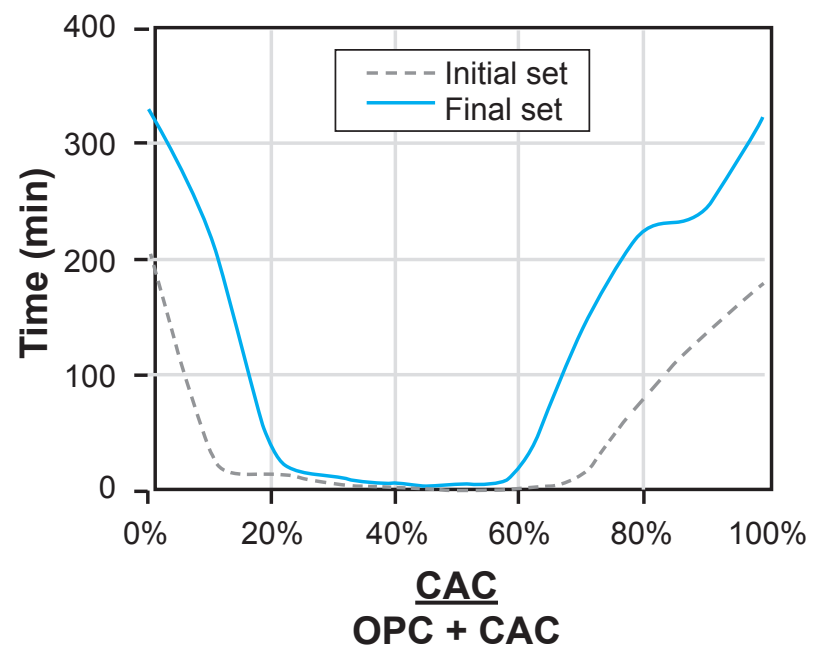

Figure 11: Schematic illustration of how the $\mathrm{CAC} /(\mathrm{CAC}+\mathrm{OPC})$ ratio influences the binary system $\mathrm{OPC} / \mathrm{CAC}$ setting time [66].

Although the barrier around $\mathrm{C}_{3} \mathrm{~A}$ is unstructured, the rapid ettringite development can cause its deposition around the $\mathrm{C}_{3} \mathrm{~S}$ phase of Portland cement, also forming a barrier that causes 'poisoning' on this silicate surface, slowing or blocking the hydration and C-S-H formation. This mainly affects the strength development over time, which depends on the hydration of silicates $[32,68,69]$. This delay or blockage depends on the ratio between the two binders. For CAC contents of around $15 \%$ of the total binders, silicate hydration occurs late, but if there is an increase of this content, the system is subject to blockage of the silicate hydration [35]. Delay of silicates hydration can be offset by calcium sulfate addition in the system $[35,70]$. In contrast, this addition can cause a setting time to increase [70]. Moreover, as the calcium sulfate source of Portland cement, the extra $\mathrm{CaSO}_{4}$ source is also an important topic to be studied, more specifically related to dimensional stability as explained ahead. Fig. 12 compares ettringite and C-S-H development for the Portland cement system, binary OPC/ $\mathrm{CAC}$ system, and ternary $\mathrm{OPC} / \mathrm{CAC} / \mathrm{CaSO}_{4}$ system during early hydration. It is possible to observe the delay of C-S-H 
formation in the binary system and the resumption for the first hours when calcium sulfate is added in the ternary system. This resumption is influenced by the calcium sulfate dosage, which affects hydration, as shown in Fig. 13. For a fixed CAC amount, the $\mathrm{CaSO}_{4}$ increase causes the return of the $\mathrm{C}_{3} \mathrm{~S}$ heat flow to a position close to the pure Portland cement. This is exemplified in Fig. 13, in which the authors [35] found that $5 \%$ of calcium sulfate in a ternary system $\mathrm{OPC} / \mathrm{CAC} /$ $\mathrm{CS}$ in a proportion of 71/24/5 were able to shift the $\mathrm{C}_{3} \mathrm{~S}$ peak back to its original position around $5 \mathrm{~h}$.

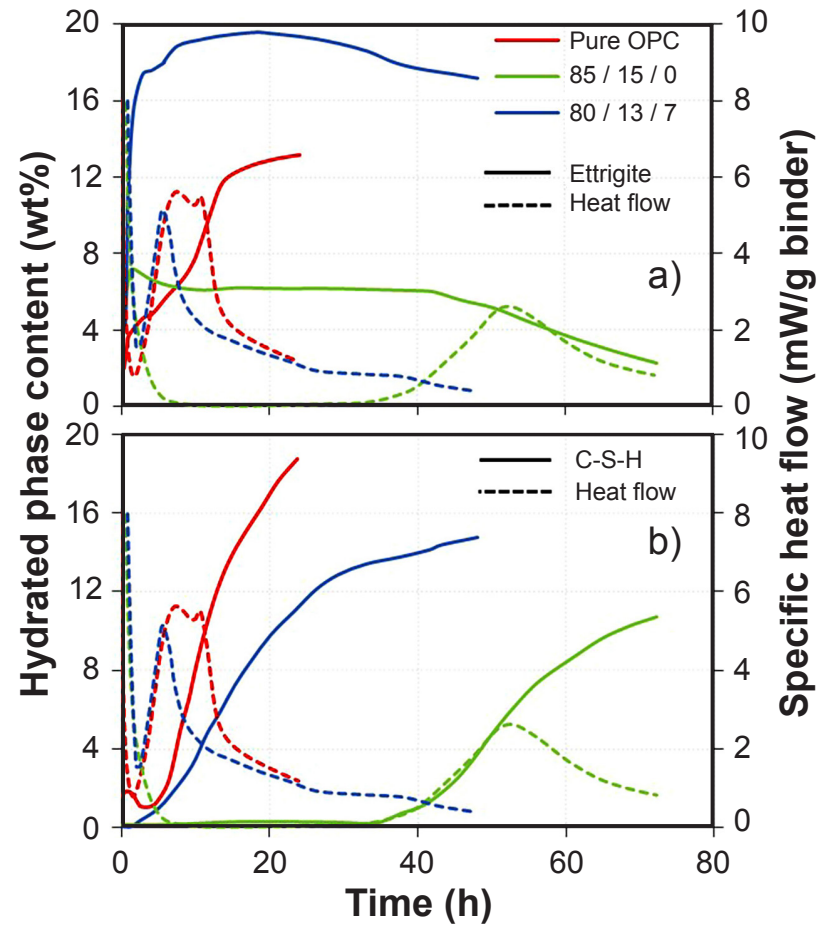

Figure 12: Hydration heat and C-S-H and ettringite development in pastes with pure Portland cement, binary OPC/CAC (85/15), and ternary $\mathrm{OPC} / \mathrm{CAC} / \mathrm{CaSO}_{4}(80 / 13 / 7)$ (adapted from [67]).

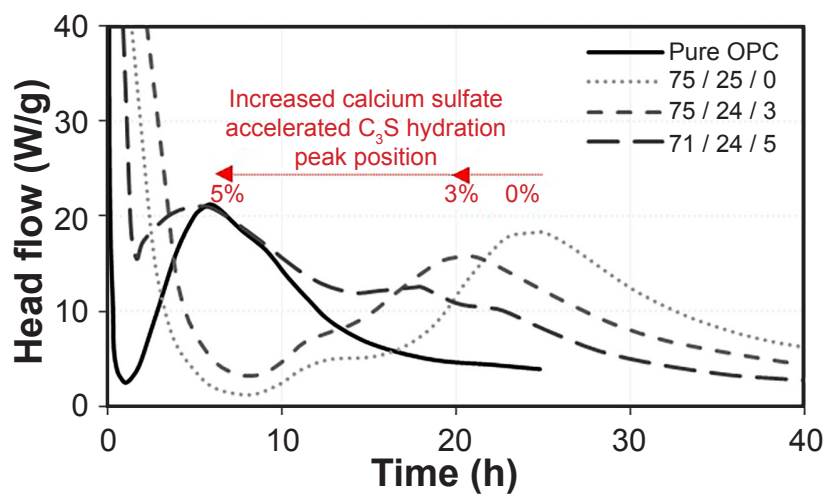

Figure 13: Hydration heat for pure OPC and ternary OPC/ $\mathrm{CAC} / \mathrm{CaSO}_{4} \cdot 1 / 2 \mathrm{H}_{2} \mathrm{O}$ with different dosages of calcium sulfate (hemihydrate): 75/25/0,73/24/3, and 71/24/5 (adapted from [35]).

Rheological behavior and influence of reaction kinetics: rheology, by definition, is the science that studies the flow and deformation of materials when subjected to a certain external mechanical stress [71]. The rheological behavior of a self-leveling mortar (or concrete) must be characterized by sufficiently low yield stress that allows the material to flow under its own weight $[72,73]$. The viscosity level influences the flow velocity and consequently how fast the material spreads when poured: the lower the viscosity, the faster the application. The viscosity dependence with the shear rate has a minor influence on the self-leveling characteristic, but Bingham or shear-thinning behaviors are more adequate (than shear-thickening) when the material is transported by pumping prior to the application [72]. Fig. 14 exemplifies rotational rheometry flow curves of self-leveling mortars (SLM), comparing them with two other types, cementitious tile adhesives (CTA) and renders, all tested in the same conditions.

\begin{tabular}{cccccccccc}
\hline $\begin{array}{c}\text { Mortar rheological } \\
\text { parameters }\end{array}$ & \multicolumn{2}{c}{$\begin{array}{c}\text { Self-leveling } \\
\text { (SLM) }\end{array}$} & \multicolumn{2}{c}{$\begin{array}{c}\text { Adhesive } \\
\text { (CTA) }\end{array}$} & \multicolumn{3}{c}{$\begin{array}{c}\text { Rendering } \\
\text { (Render) }\end{array}$} \\
& A & B & C & A & B & A & B & C \\
\hline Yield torque (N.mm) & 39 & 7.9 & 0.3 & 313 & 212 & 2366 & 1163 & 936 \\
\hline Plastic viscosity* (N.mm.s) & 73 & 232 & 311 & 136 & 42 & 454 & 321 & 128 \\
\hline
\end{tabular}
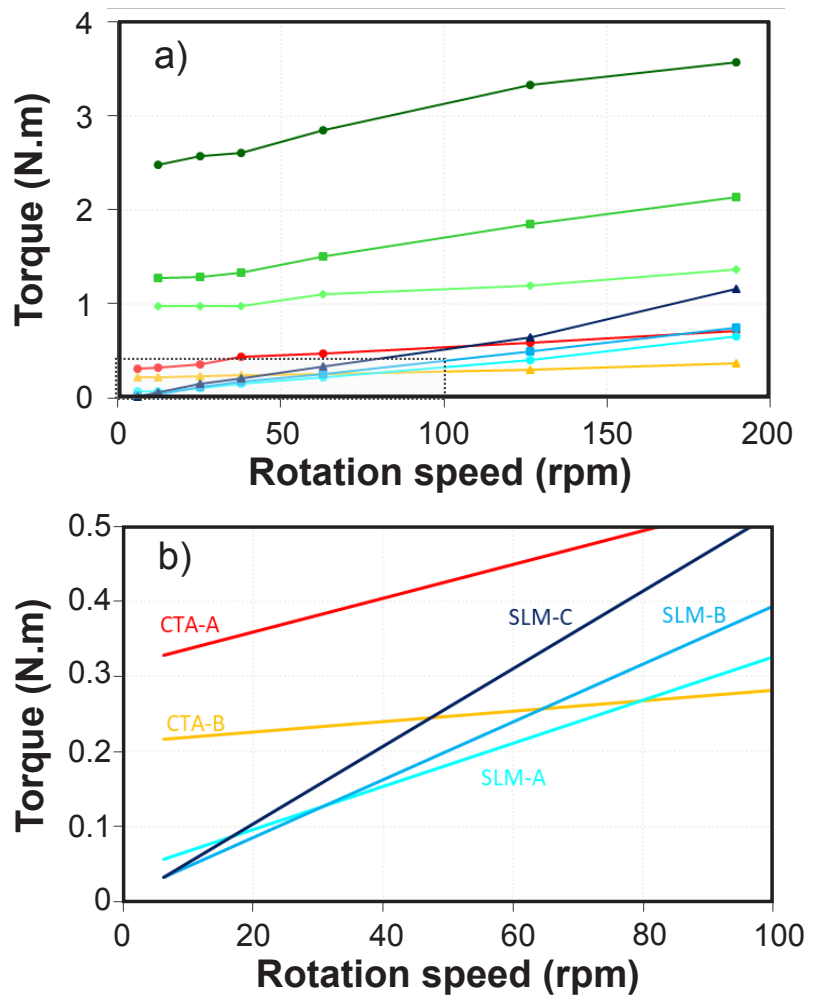

Figure 14: Rheological behavior demonstrated by torque versus rotation speed for some types of mortars: factory-produced Brazilian render mortars: render and/or masonry (render-A), onecoat decorative render (render-B), and internal render (render-C); cementitious tile adhesive mortars: ACI (CTA-A) and ACIII (CTA-B) types; and self-leveling calcium aluminate-containing mortars from BASF-Germany with different combinations of admixtures: SLM-A, SLM-B, and SLM-C. In (a), results for all mortars and table with yield torque and plastic viscosity (* equivalent to plastic viscosity based on torque vs. rotation curves [74]); in (b), linear fits for CTA and SLM mortars with zoom in values of torque up to $0.5 \mathrm{~N}$.m and rotation speed up to $100 \mathrm{rpm}$. All tests were performed in a rotational rheometer with planetary setup and attritor impeller, step-based shear cycle up to $190 \mathrm{rpm}$ [75] (data from [76-78]). 
It is clearly observed that for each application, the key property of rheological behavior is the yield torque (directly related to yield stress), detailed in the inserted table in Fig. 14a, where SLMs exhibit very low values compared with CTA and renders, but slightly accentuated plastic viscosity mainly due to the need to avoid segregation. The rheological behavior of cementitious products such as self-leveling mortars must be controlled to obtain the required flowability and, at the same time, to ensure segregation resistance (bleeding and particle segregation), which means that rheological parameters cannot be reduced without control. Many intrinsic factors of the mortar affect the rheological behavior, such as water amount, reaction kinetics influenced by the binder types and proportions, presence of additives as dispersants or setting time controllers, particle size distribution, among others. Fig. 15 exhibits yield stress versus viscosity scheme highlighting regions that result in: (blue) low workability for self-leveling applications, (pink) segregation due to very low yield stress and/or viscosity, and (white) adequate self-leveling behavior [72, 79].

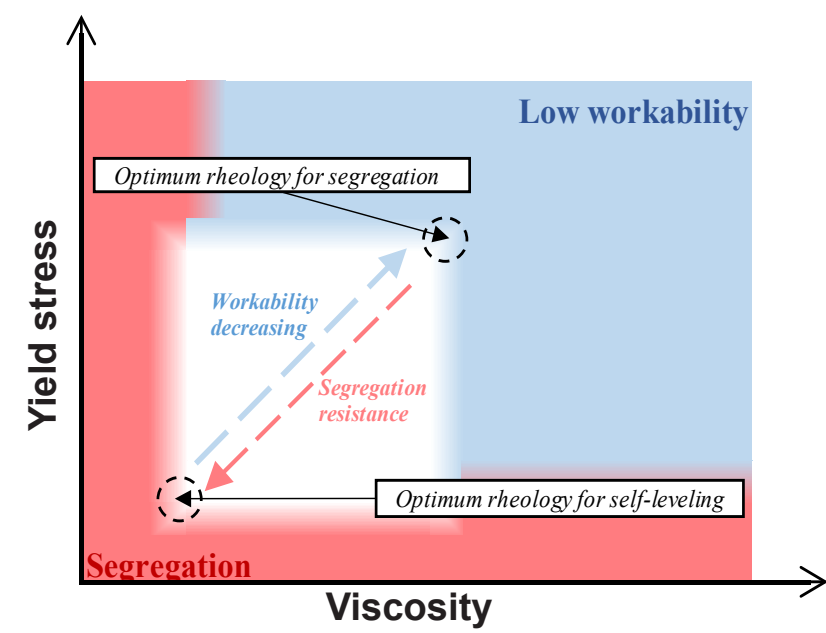

Figure 15: Schematic illustration of rheological behavior in regions with different performances in self-leveling compositions according to yield stress and viscosity (adapted from [79]).

Assuming that the product has optimum flowability and segregation resistance parameters, a determining factor is the maximum heat flow, resulting from the chemical reaction of the components with high reactivity, which influences the initial flow, the flow over time, and, therefore, the open time. Calcium aluminate and calcium sulfate react in the first few minutes for ettringite formation and release a high amount of heat, causing the decrease of free water. Besides decreasing the fluidity [80], such a feature is also a reason for shrinkage [8]. Fig. 16 shows a trend that the higher the maximum heat flow during the initial dissolution and precipitation period in the first $5 \mathrm{~min}$, the lower the initial flowability for different calcium sulfate types. This result can take into account the solubility of calcium sulfate used since both hemihydrates showed higher maximum heat flows, probably because they are more soluble than the other types, releasing more heat in this first stage. However, it is important to note that even the flowability and heat flow is not solely dependent on calcium sulfate solubility but also on particle size and surface area of these components, which could influence the fact that $\beta$-hemihydrate causes a much less initial flow than $\alpha$-hemihydrate. This knowledge is not only for selfleveling application as exemplified in Fig. 16 but for any cementitious material which the ternary system can be used and depends on an accurate control of rheological behavior, such as self-compacting concrete and 3D printing.

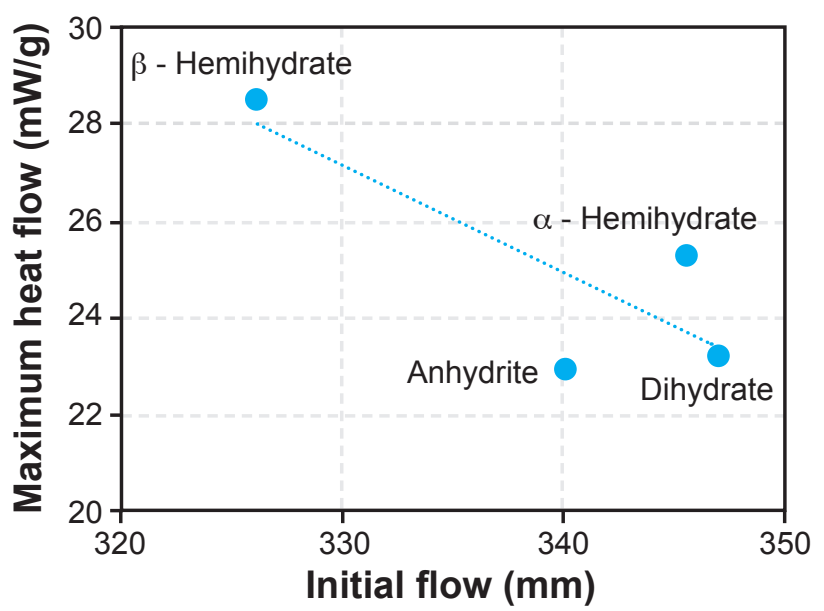

Figure 16: Comparison between maximum heat flow after 5 min of mixing and diameter of initial flow in self-leveling mortars with ternary system $\mathrm{OPC} / \mathrm{CAC} / \mathrm{CaSO}_{4} \cdot \mathrm{xH}_{2} \mathrm{O}$ as $50 / 32 / 18$ for different calcium sulfate types (data from [8]).

Regarding the ternary dosage, Fig. 17a demonstrates that as the amount of CAC increases, the greater the heat accumulated in the first hours of hydration. However, for the system with $25 \% \mathrm{CAC}$, as the amount of calcium sulfate increases, the initial heat flow decreases and may lead to increased initial flow within the first few minutes (Fig. 17b). Thus, by correlating the graphs, increasing CAC may decrease initial flow and, for a fixed amount of CAC, increasing calcium sulfate content lead to larger flow values. Due to the consumption of free water by the initial reactions, two solutions are possible for the improvement of self-flowability: increase of the water content and/or increase of the dispersant content. To avoid a reduction in strength and the likelihood of increased phase separation, increasing the dispersant content can be considered a better solution. This is because, regardless of the stabilization mechanism, dispersants create barriers by being adsorbed on the cement grains surface, which prevents agglomeration of the particles and thus reduces the energy required to promote flow in the system [72]. Fig. 18 exhibits the demand for dispersant admixture to maintain flowability as the CSA-based expansive admixture amount increases. The expansion mechanism of this admixture is the same as the CAC-based, i.e., expansion by ettringite formation. However, the optimum dispersant dosage may be exceeded, i.e., above a certain value, it no longer affects flowability and can cause segregation. Thus, other admixtures such as tartaric acid, citric acid, or trisodium citrate can also be employed to retard ettringite formation and ensure longer 
flow, as well as improving the development of strength [32]. The choice of retarder additive and binder proportion, as well as the content used, highly affect the self-leveling mortar viscosity and reactivity over time. In Fig. 19, the CAC-rich formulation $4 / 20 / 7\left(\mathrm{OPC} / \mathrm{CAC} / \mathrm{CaSO}_{4} \cdot 1 / 2 \mathrm{H}_{2} \mathrm{O}\right)$ shows how the use of citric or tartaric acid affects the apparent viscosity over time, demonstrating that tartaric acid is more effective in long-term. Meanwhile, the OPC-rich formulations with binder compositions 16/8/4 and 19/12/7 (OPC/CAC/CaSO $\left.{ }_{4}\right)$ show that, although the 19/12/7 has more binder content, the $0.20 \%$ citric acid is more effective than $0.12 \%$ at long-term, also increasing the setting time. Moreover, it is possible to observe how the apparent viscosity values are affected by the accumulated heat flow of the systems in the first 30 min for CAC-rich and $60 \mathrm{~min}$ for OPC-rich formulations, demonstrating that $\mathrm{CAC}$-rich is highly more reactive than OPC-rich for these additive configurations.
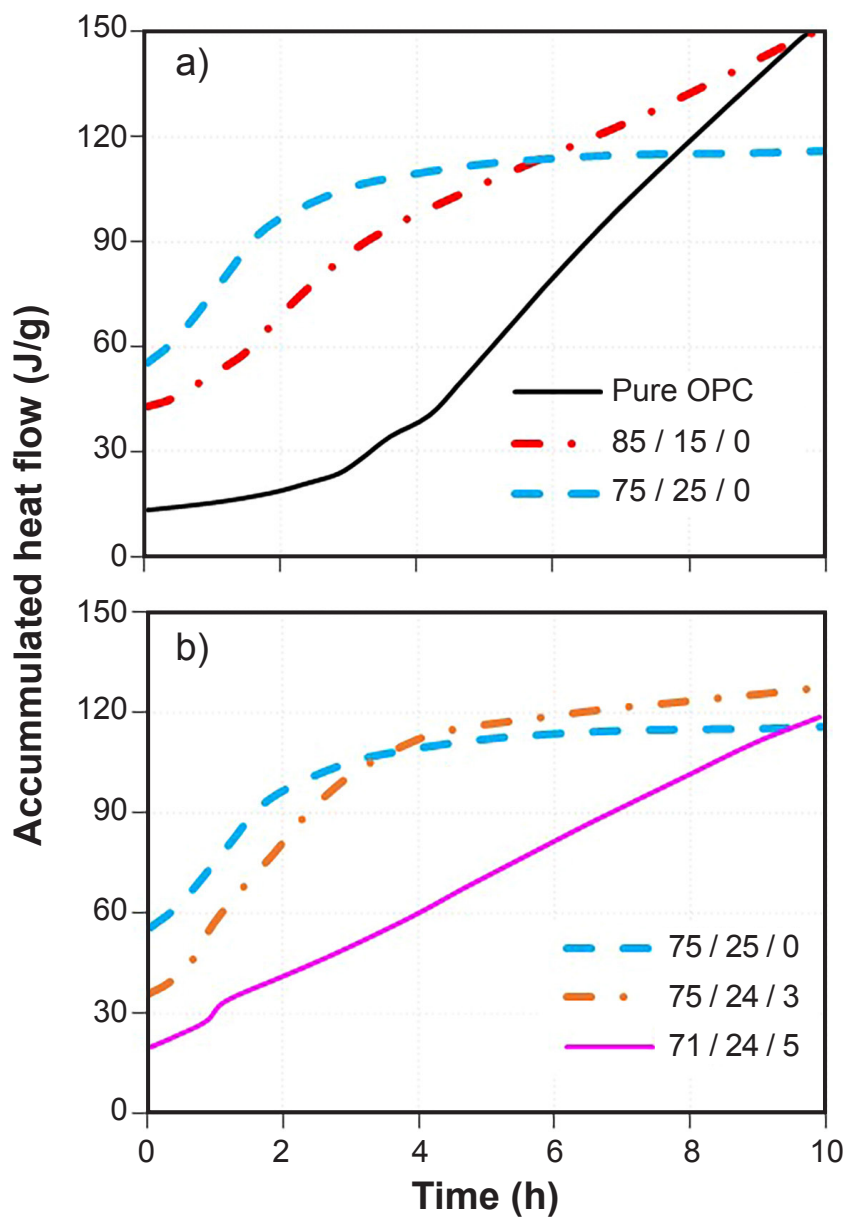

Figure 17: Accumulated heat flow by time in the first $10 \mathrm{~h}$ for compositions $\mathrm{OPC} / \mathrm{CAC} / \mathrm{CaSO}_{4} 1 / 2 \mathrm{H}_{2} \mathrm{O}$ showing the influence of: a) CAC content in pure OPC and binaries $85 / 15 / 0$ and $75 / 25 / 0$; and b) $\mathrm{CaSO}_{4} \cdot 1 / 2 \mathrm{H}_{2} \mathrm{O}$ content in compositions $75 / 25 / 0,73 / 24 / 3$, and 71/24/5 (adapted from [35]).

Strength development: as observed in reaction kinetics, CAC dosing as a substitute for Portland cement affects the hydration of the silicate phase, which can be blocked. Fig. 20 demonstrates that for a proportion of 80/20 (OPC/ $\mathrm{CAC}$ ), the compressive strength up to $8 \mathrm{~h}$ after mixing is

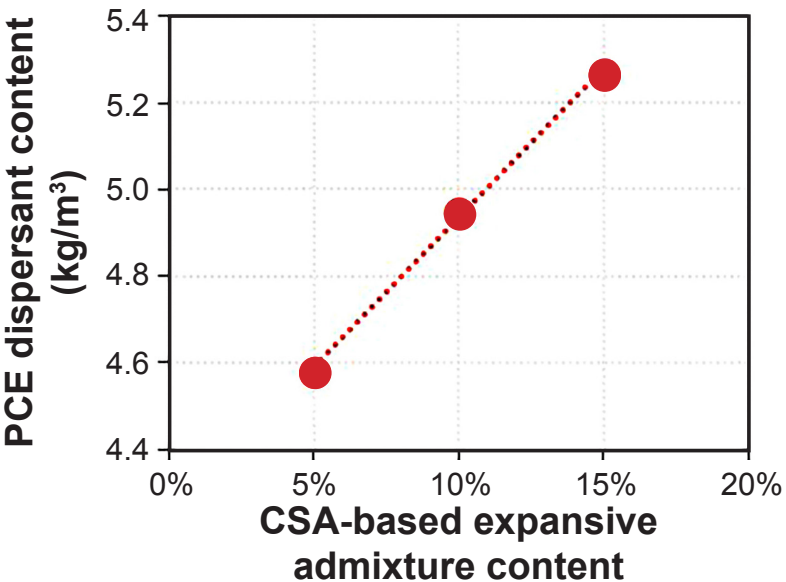

Figure 18: Polycarboxylate-based dispersant content as a function of CSA-based expansive additive content in order to remain constant the slump flow testing in high-performance selfcompacting concretes (data from [80]).
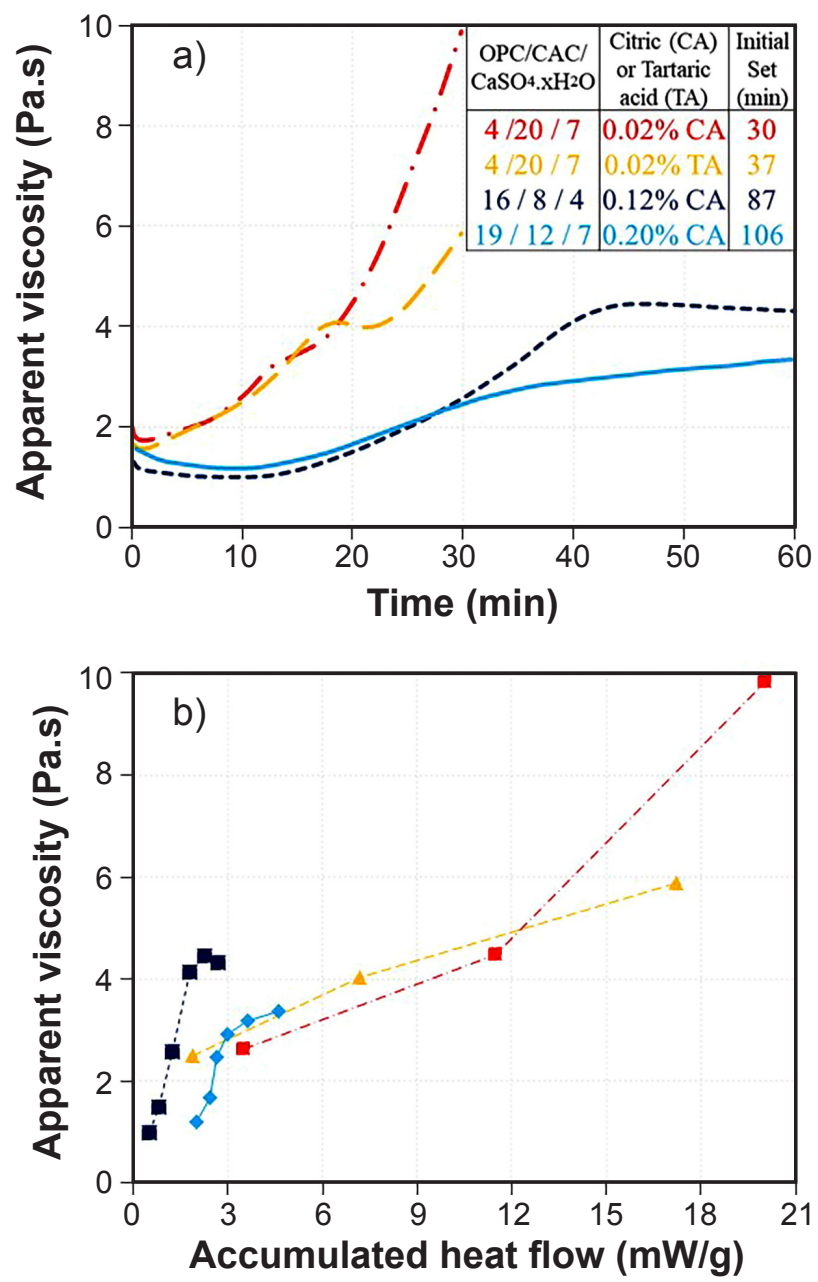

Figure 19: Apparent viscosity at a shear rate of $15 \mathrm{~s}^{-1}$ as a function of time (a) and accumulated heat flow (b) of self-leveling mortars, a CAC-rich formulation with binder composition OPC/CAC/ $\mathrm{CaSO}_{4} \cdot 1 / 2 \mathrm{H}_{2} \mathrm{O}$ of $4 / 20 / 7$ comparing citric and tartaric acids (during $30 \mathrm{~min}$ ) and two OPC-rich with binder compositions OPC/CAC/ $\mathrm{CaSO}_{4}$ of 16/8/4 and 19/12/7 comparing citric acid contents (during $60 \mathrm{~min}$ ) (adapted from [81]). 


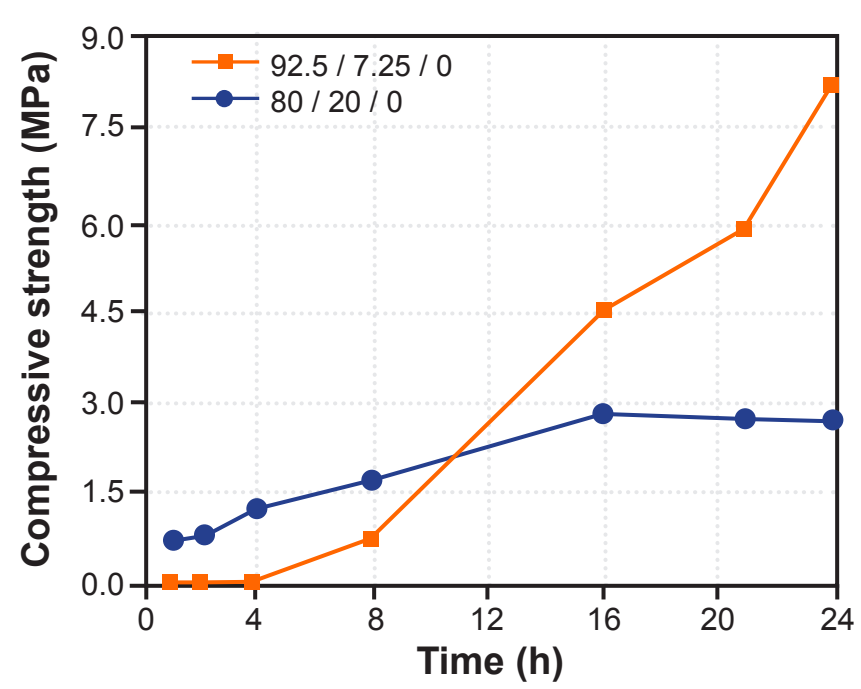

Figure 20: Compressive strength development in cementitious materials of the binary system OPC/CAC (92.5/7.25 and 80/20) (data from [69]).

\section{Total binder content}

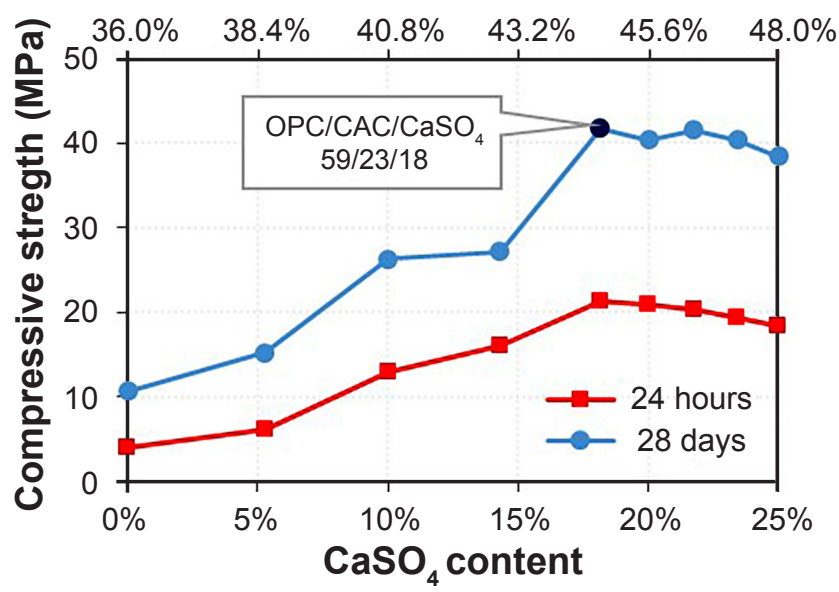

Figure 21: Compressive strength at $24 \mathrm{~h}$ and 28 days for selfleveling mortars with increasing anhydrite content added in the ternary system $\mathrm{OPC} / \mathrm{CAC} / \mathrm{CaSO}_{4}$ in the ratios $72 / 28 / 0,68 / 26 / 5$, $65 / 25 / 10,62 / 24 / 14,59 / 23 / 18,58 / 22 / 20,57 / 22 / 22,55 / 21 / 23$, and $54 / 21 / 25$ (adapted from [82]).

significantly higher than for the formulation with less CAC 92.5/7.5, but from $12 \mathrm{~h}$ onwards, the strength of the 92.5/7.5 formulation surpasses that of CAC-richer material and gets approximately 3 times higher after $24 \mathrm{~h}$. Thus, the addition of calcium sulfate is needed to ensure $\mathrm{C}_{3} \mathrm{~S}$ hydration and, consequently, strength development. Fig. 21 exhibits how increasing anhydrite content in a self-leveling mortar affects strength after $24 \mathrm{~h}$ and 28 days. It is observed that up to $18 \%$ of calcium sulfate, an increase in strength occurs, and after this value, it decreases slightly. However, for each system, there is a limited value of calcium sulfate to be added to achieve maximum strength.

Length change in ternary system OPC-CAC-CaSO${ }_{4}$ : shrinkage compensation is the main aspect for which the ternary system is required in self-leveling mortars. Fig. 22 shows the traditional profile of a binary system, in which no

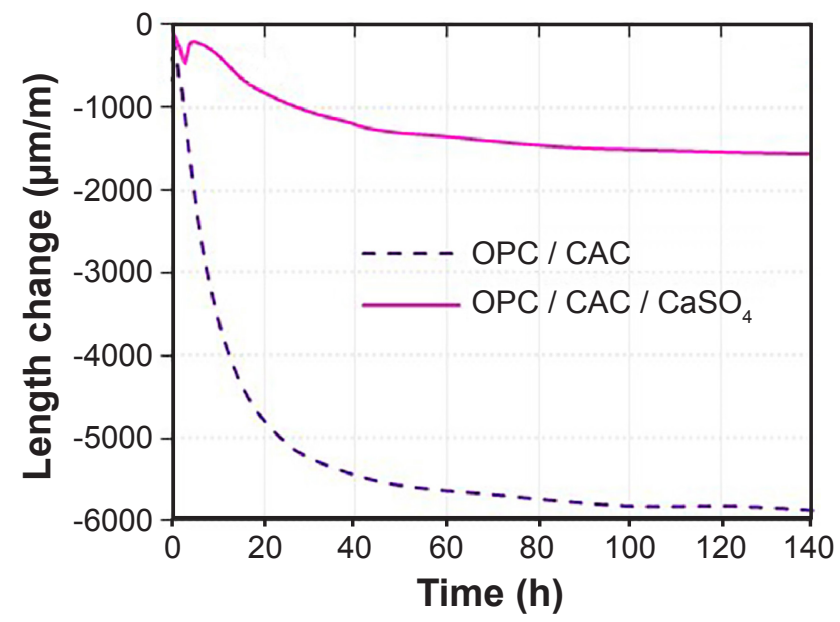

Figure 22: Schematic illustration of length change of a binary system OPC/CAC and a ternary system $\mathrm{OPC} / \mathrm{CAC} / \mathrm{CaSO}_{4}$ at room temperature in a humid condition (adapted from [24]).

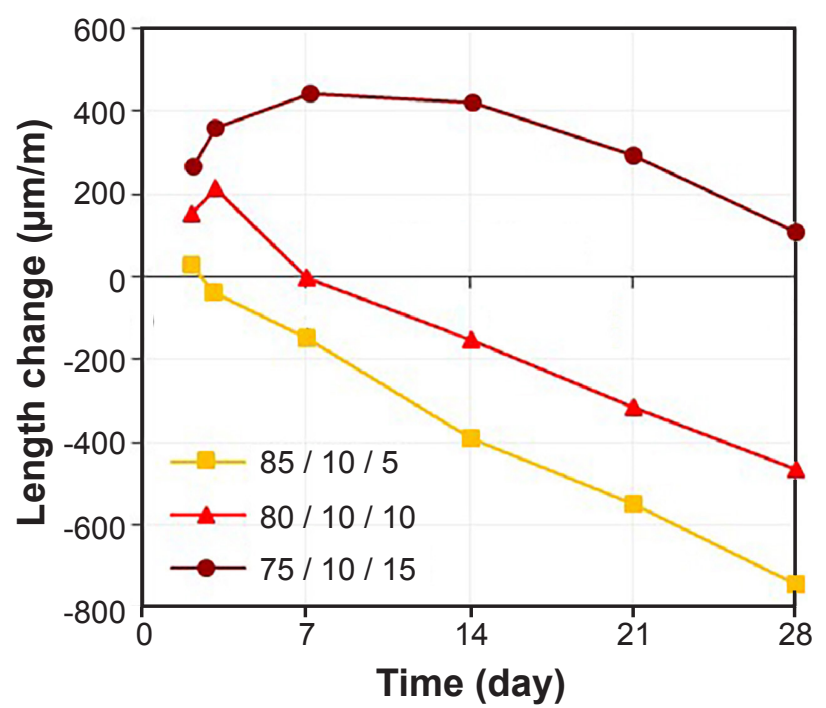

Figure 23: Length change of self-leveling mortars with ternary system $\mathrm{OPC} / \mathrm{CAC} / \mathrm{CaSO}_{4}$ in dosages of $85 / 10 / 5,80 / 10 / 10$, and $75 / 10 / 15$ at a relative humidity of $95 \%, 22{ }^{\circ} \mathrm{C}$ up to $24 \mathrm{~h}$ (adapted from [9]).

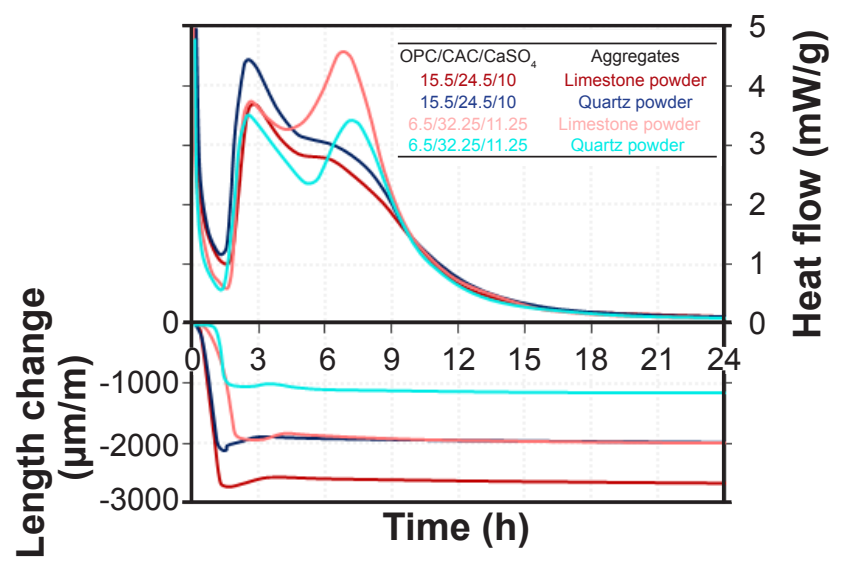

Figure 24: Heat flow and early length change of the ternary system with limestone or quartz powder during the first $24 \mathrm{~h}$ of hydration (adapted from [83]). 
compensation is observed, and of a ternary system, which shows the compensation that occurred in the early hours, preventing the accentuated shrinkage over time. The calcium sulfate amount added also affects the length change. Fig. 23 shows that the higher the anhydrite content, the greater is the expansion in the early ages; thus, the shrinkage intensity over time is reduced. In addition to binder proportions, the length change is also influenced by the aggregates used (Fig. 24). Changing limestone powder for quartz powder affects the length change as well as the heat flow evolution: quartz can decrease the heat flow and shrinkage during the first $24 \mathrm{~h}$. Not only different aggregates can influence these properties, but also the presence of redispersible additive powder tends to reduce the plastic shrinkage and to increase the expansion [83].

Ternary system OPC-CAC-CaSO${ }_{4}$ expansion mechanism: the induced expansion mechanism occurs during the first hours of hydration through the controlled ettringite formation within the cementitious matrix. Thus, the shrinkage is compensated by the volume increase caused by the hydrates that cause a restriction to this expansion; that is, they induce compressive stress that compensates the tensile stress generated by drying shrinkage during the late ages. In addition to the pressure caused by the increase in matrix volume, the ettringite formation absorbs a large amount of water on its surface, removing the water from the pores of the system and avoiding it to be free to dry out $[9,24,84]$, hence, diminishing the driving force of drying shrinkage. The length change is the result of two opposite processes: the expansion determined by the ettringite formation in the system and the shrinkage caused mainly by drying of the mortar. The magnitude of these processes is influenced by $\mathrm{CAC} / \mathrm{CaSO}_{4}$ and $\mathrm{OPC} /\left(\mathrm{CAC}+\mathrm{CaSO}_{4}\right)$ ratios, calcium sulfate type and solubility, Portland cement characteristics, and curing conditions [85]. The expansion process can be divided into 3 stages (Fig. 25) [24]: stage 1: dormant period; anhydrous binders are dissolved, chemical activity has not started yet, and plastic shrinkage is observed; stage 2: precipitation period; chemical reactions begin and massive precipitation

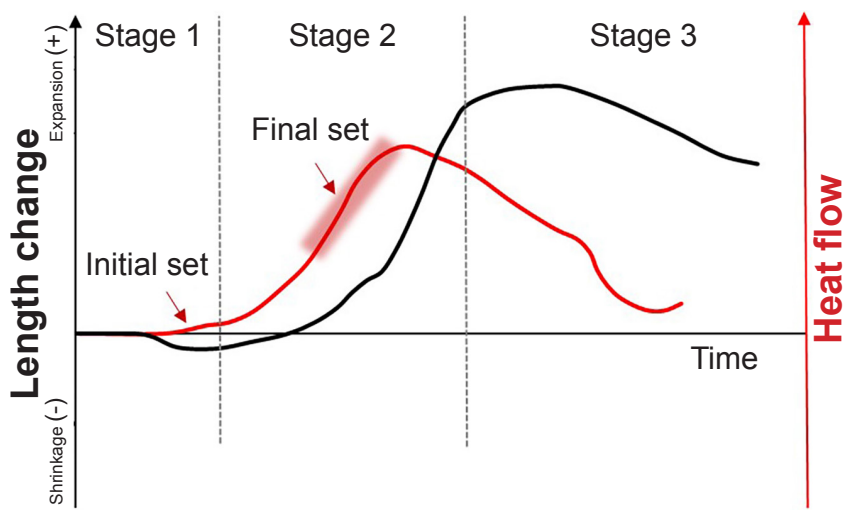

Figure 25: Schematic illustration of length change and heat flow as a function of setting time of a cementitious material having shrinkage compensation by ettringite formation (adapted from [24, 86]). of ettringite is accompanied by volume increase, i.e., expansion; when Portland cement and calcium aluminate are analyzed, shrinkage is observed; in this stage, the microstructural development begins; and stage 3: ettringite formation reaction is finished, and the length change is affected basically by drying shrinkage; if the chemistry is unbalanced, further expansion may occur at this stage; in general, after this period the other anhydrous phases of the system are hydrated but considerable expansion is not observed. In self-leveling cementitious mortars, the performance is highly dependent on environmental conditions such as humidity and temperature, and stage 2 is the main one affected by these variations since this is also the stage of main ettringite development [24].

Calcium sulfate type and its influence on length change and early strength: to achieve enough expansion that compensates shrinkage and ensures a microstructure with the desired porosity and consequently mechanical properties, it is important that the balance between $\mathrm{CaO}, \mathrm{Al}_{2} \mathrm{O}_{3}$, and $\mathrm{SO}_{3}$ containing components is such that the $\mathrm{SO}_{3}$ amount is low when compared to the $\mathrm{Al}_{2} \mathrm{O}_{3}$ amount. Thus, in a balanced system with controlled length change, ettringite hydrate can grow in a needle-shape, thin, and slender, rather than massive, hexagonal, and short prismatic formats, with adequate speed and quantity in order to achieve a rapid and controlled shrinkage compensation early during the initial microstructural development. Such performance depends on the system type being used for compensation and the dissolution rate of each raw material [9]. Thus, the raw material proportion should be balanced, mainly limiting the dosage of calcium sulfate, as it determines the sulfate content available for ettringite formation [87]. Fig. 26 shows the two types of ettringite that can be formed.

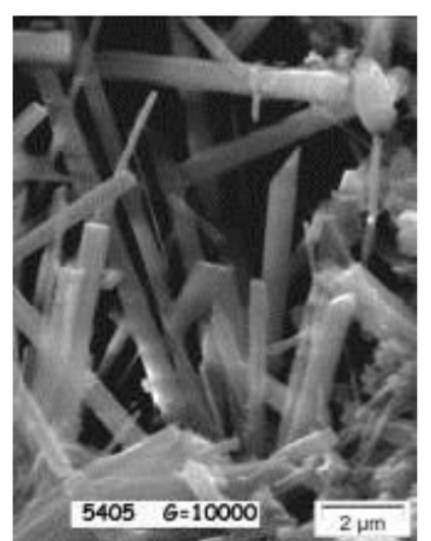

a) Fine/Elongated needles

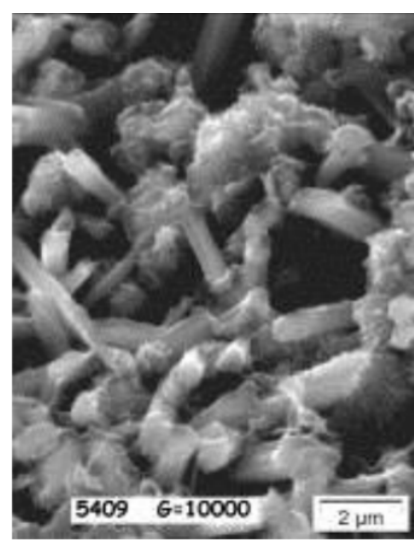

b) Massive ettringite shape
Figure 26: Scanning electron microscopy (SEM) images of: a) fine/ elongated ettringite needles; and b) massive ettringite [5].

A way to obtain the amount of calcium sulfate required for the ettringite formation is through stoichiometric equations such as the extent of reaction, which represents the expansive cement reactivity percentage in the expansive admixture blend (the aluminate supplier) controlled by the sulfates [ 88 , 89]. However, this method requires accurate characterization 
of raw materials such as calcium sulfate and $\mathrm{C}_{3} \mathrm{~A}$ phase contents in Portland cement, as well as the CA phase content in calcium aluminate. Usually, such information is not provided by the manufacturers, and sophisticated equipments are required to obtain that. Thus, due to different solubilities between calcium sulfate types demonstrated in Fig. 10, the type added in the OPC-rich ternary system can affect the ion balance and length change [8, 9, 85]. Fig. 27 shows results of ternary system self-leveling mortars OPCCAC- $\mathrm{xCaSO}_{4}(50 / 32 / 18, \mathrm{CAC} 40 \%$ alumina) comparing the three types of calcium sulfate in addition to compressive strength at 6 and $24 \mathrm{~h}$. The dimensional stability, as well as higher early compressive strength, were achieved only using anhydrite, whereas using dihydrate, there was a considerable expansion at the beginning, and with hemihydrate, the expansion was so large that it was above the equipment measuring capacity. Dimensional stability occurs because $\mathrm{Ca}^{+}, \mathrm{SO}_{4}^{2-}$, and $\mathrm{Al}(\mathrm{OH})_{4}^{-}$ions are balanced due to the low solubility of anhydrite, which favors ettringite precipitation and growth in a needle shape at the interfaces of hydrated products forming a firm and dense structure $[9,32,35,90$, 91]. In other cases, due to the hemihydrate and dihydrate high dissolution rates compared to anhydrite, $\mathrm{Ca}^{+}$and $\mathrm{SO}_{4}^{2-}$ ions are present in higher concentration than $\mathrm{Al}(\mathrm{OH})_{4}^{-}$, which causes the ettringite formation in greater quantity and in short, hexagonal, and prismatic format $[8,9,85$, 90]. This high amount of ettringite causes an exaggerated expansion, which can bring cracking in the specimens and low values for early strength (Fig. 27). A large amount of ettringite formed using hemihydrate compared to anhydrite can be observed in ettringite content analysis over time. For a ternary system $\mathrm{OPC} / \mathrm{CAC} / \mathrm{xCaSO}_{4}(77.5 / 15 / 7.5)$ at $20{ }^{\circ} \mathrm{C}$, during the first $3 \mathrm{~h}$ the ettringite content achieves values around $15 \%$ and stabilizes at $22 \%$ after $72 \mathrm{~h}$ in an anhydrite system, while using hemihydrate, at $3 \mathrm{~h}$ the value is $25 \%$ and highly decreases to $4 \%$ at $72 \mathrm{~h}$ in a hemihydrate system. This shows how ettringite content varies over time for

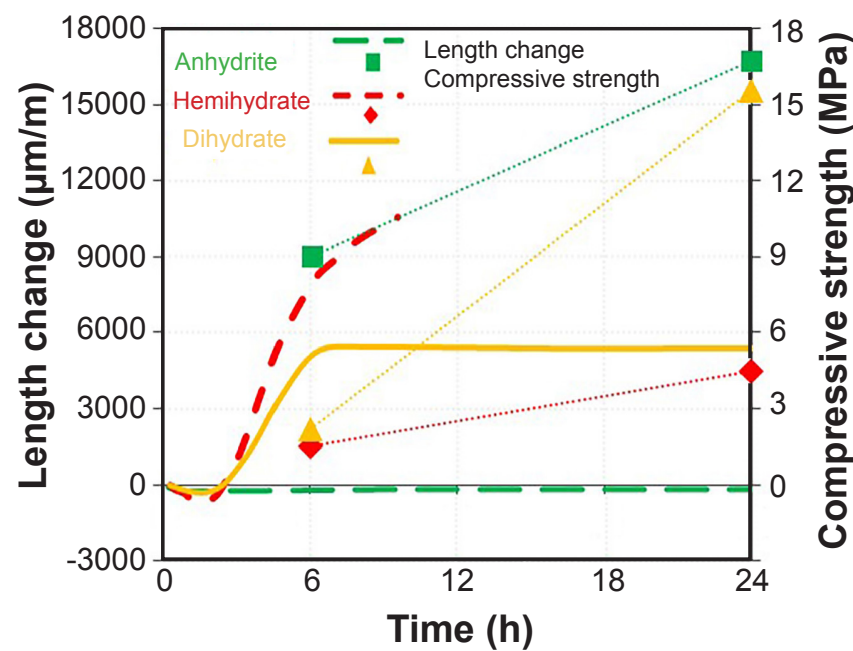

Figure 27: Length change and early compressive strength of selfleveling mortars with different types of calcium sulfate added in the proportion of binders in ternary system $\mathrm{OPC} / \mathrm{CAC} / \mathrm{CaSO}_{4}$ of 50/32/18 (adapted from [8]). hemihydrate and anhydrite, showing the early structuring peak for hemihydrate and the drop due to calcium sulfate depletion and the transformation of ettringite into calcium monosulfate [92].

\section{COMPARISON BETWEEN DIMENSIONAL STABILITY SOLUTIONS}

As described above, the ternary system OPC-CAC$\mathrm{CaSO}_{4}$ is not the only system used to prevent shrinkage and consequently cracking in cementitious systems. The following studies compare solutions in order to expose their efficiency and suitability according to the type of cementitious system considered. The studies compared solutions such as Portland cement partial replacement, mechanical restraint by polyethylene and steel fibers, shrinkage reducer (SRA), CaO-based expander admixture, and shrinkage compensation by ettringite formation through the CSA-based expansive admixture (K-type). Unfortunately and peculiarly, the ternary system OPCCAC-CaSO ${ }_{4}$ was not found in comparative studies.

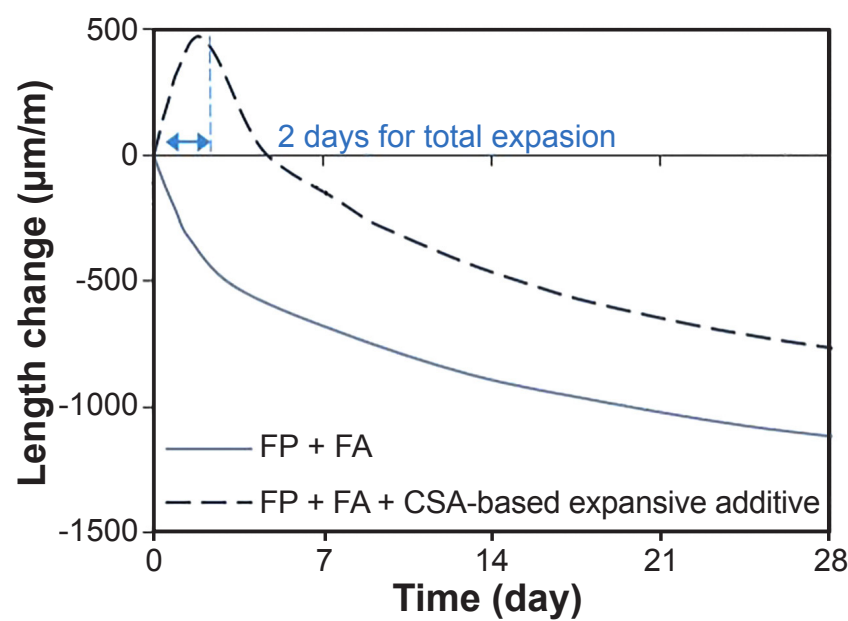

Figure 28:Length change of aconventional 'SHCC-strain-hardening cement composite' with $0.75 \%$ polyethylene fiber (FP) and $0.75 \%$ hooked steel fiber (FA) by volume, and another also with these fibers but with $10 \%$ of Portland cement replaced by CSA-based expansive additive, at $20{ }^{\circ} \mathrm{C}$ and $50 \%$ relative humidity (adapted from [93]).

CSA-based expansive cement vs. polyethylene and steel fibers: as the ternary system OPC-CAC-CaSO ${ }_{4}$, the calcium sulfoaluminate-based expansive admixture also compensates shrinkage through an initial expansion caused by ettringite formation. Fig. 28 demonstrates how the initial expansion enhances the shrinkage decreasing effect in a cementitious system compared to the same material with only mechanical restrain by polyethylene and steel fibers [93].

CaO-based expander admixture vs. shrinkage reducer (SRA): Fig. 29 demonstrates the efficiency of the CaObased expander admixture versus the admixture that only reduces the shrinkage effect of the cementitious system. The expander admixture promotes an initial expansion caused by $\mathrm{Ca}(\mathrm{OH})_{2}$ formation. 
CSA-based expansive cement vs. CaO-based expander admixture: the CSA-based expansive admixture (K-type) is compared to the CaO-based expander and to a system without expansive components in the following study. Fig. 30 shows that both achieve similar properties with respect to length change after 7 days submerged in water and according to the dosages displayed. The main difference between CSA and $\mathrm{CaO}$-based systems is the expansion rate: the $\mathrm{CaO}$-based expander admixture system expands at a faster rate [95].

Comparative analysis of solutions with the ternary system $\mathrm{OPC}-\mathrm{CAC}-\mathrm{CASO}_{4}$ : basically, for some dosages considered, materials sources and conditions imposed, it

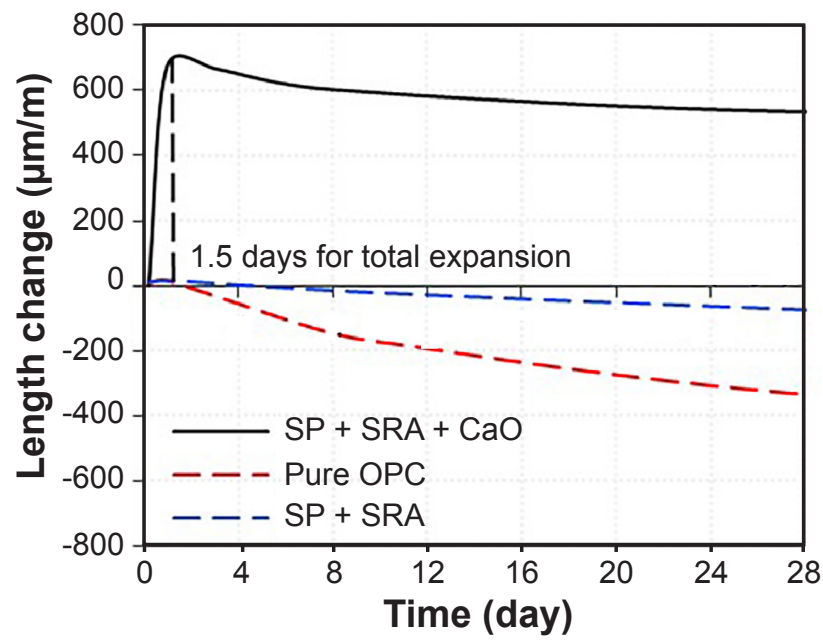

Figure 29: Length change of a cementitious system with $7 \%$ of polyacrylate superplasticizer (SP+SRA), which has water and drying shrinkage reducing effects, another with $7 \% \mathrm{SP}+\mathrm{SRA}$ plus $25 \% \mathrm{CaO}$ expansion additive in $\mathrm{kg} / \mathrm{m}^{3}(\mathrm{SP}+\mathrm{SRA}+\mathrm{CaO})$, and a pure OPC as control. Curing conditions: $20{ }^{\circ} \mathrm{C}$ with polyethylene foil for 1 day and then permanent exposure to air with 55\% relative humidity (adapted from [94]). was observed that the expansion mechanism after hydration provides the best result of dimension stability, either by the formation of ettringite or calcium hydroxide. When mechanical restriction by fibers or shrinkage admixture is used, the shrinkage phenomenon is smoothed, but due to the lack of initial expansion, the system still achieves high shrinkage values over time. Although no articles were found to perform the experimental comparison of the ternary system OPC-CAC-CaSO${ }_{4}$ with other solutions, it is reasonable to assume that the ternary system would perform similar to the calcium sulfoaluminate compensating admixture. Both methods are considered expansive cements

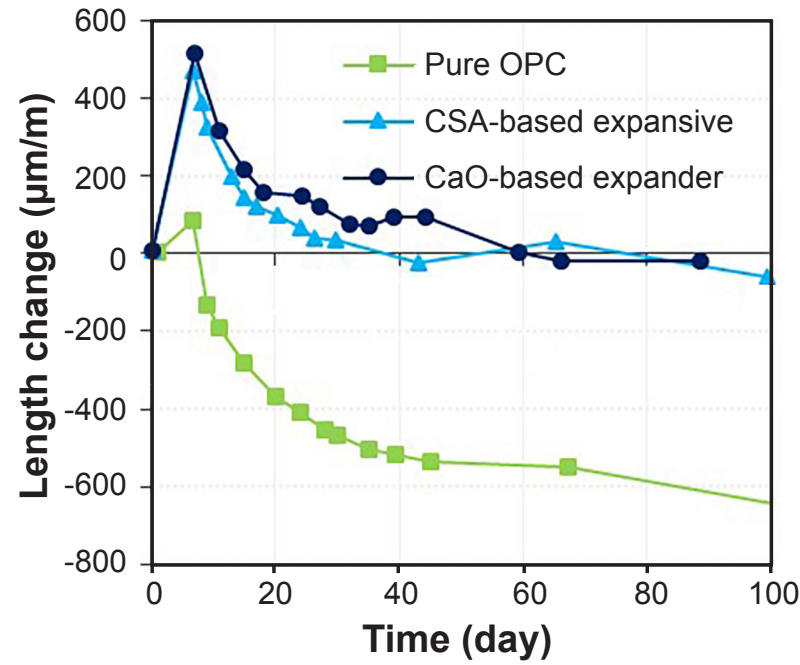

Figure 30: Length change of cementitious systems: pure Portland cement; $15 \%$ of Portland cement replaced by CSA-based expansive additive; and $6 \%$ of Portland cement replaced by $\mathrm{CaO}-$ based expander additive. The samples were demolded after $6 \mathrm{~h}$ and immersed in saturated lime water for 7 days and thereafter exposed to room conditions of $23{ }^{\circ} \mathrm{C}$ and $50 \% \mathrm{RH}$ (adapted from [95]).

Table III - Dimensional stability solutions and influences on self-leveling mortar properties (一: no significant influence; $\mathbf{\Delta}$ : improves performance; $\boldsymbol{\nabla}$ : worsens performance).

\begin{tabular}{|c|c|c|c|c|c|c|c|c|}
\hline System & Method & $\begin{array}{l}\text { Initial } \\
\text { flow }\end{array}$ & $\begin{array}{l}\text { Flow } \\
\text { retention }\end{array}$ & $\begin{array}{c}\text { Working } \\
\text { time }\end{array}$ & $\begin{array}{l}\text { Setting } \\
\text { time }\end{array}$ & $\begin{array}{l}\text { Early } \\
\text { strength }\end{array}$ & $\begin{array}{c}\text { Strength } \\
\text { development }\end{array}$ & $\begin{array}{c}\text { Dimensional } \\
\text { stability }\end{array}$ \\
\hline $\begin{array}{c}\text { Ternary system } \\
\text { OPC-CAC- } \\
\mathrm{CaSO}_{4}\end{array}$ & $\begin{array}{c}\text { Shrinkage } \\
\text { compensation by } \\
\text { ettringite }\end{array}$ & - & $\nabla$ & $\nabla$ & $\Delta$ & $\Delta$ & $\Delta$ & $\Delta \mathbf{\Delta}$ \\
\hline $\begin{array}{l}\text { CSA-based } \\
\text { expansive } \\
\text { cement }\end{array}$ & $\begin{array}{c}\text { Shrinkage } \\
\text { compensation by } \\
\text { ettringite }\end{array}$ & - & - & - & $\Delta$ & - & $\Delta$ & $\mathbf{\Delta} \mathbf{\Delta}$ \\
\hline $\begin{array}{l}\text { CaO-based } \\
\text { expander } \\
\text { admixture }\end{array}$ & $\begin{array}{c}\text { Shrinkage } \\
\text { compensation by } \\
\mathrm{Ca}(\mathrm{OH})_{2}\end{array}$ & - & - & - & - & - & $\Delta$ & $\Delta \mathbf{\Delta}$ \\
\hline $\begin{array}{c}\text { Shrinkage } \\
\text { reducer (SRA) }\end{array}$ & $\begin{array}{l}\text { Autogenous and } \\
\text { drying shrinkage } \\
\text { reduction }\end{array}$ & - & - & - & - & - & - & $\Delta$ \\
\hline $\begin{array}{l}\text { Polyethylene } \\
\text { and steel fibers }\end{array}$ & $\begin{array}{l}\text { Mechanical } \\
\text { restriction }\end{array}$ & $\nabla$ & - & - & - & - & $\Delta$ & $\Delta$ \\
\hline
\end{tabular}


according to ASTM C845:2018 standard and have the same mechanism of expansion by ettringite formation. Therefore, the ternary system OPC-CAC-CaSO ${ }_{4}$ fits into the context of shrinkage compensation and can be considered essential for dimensional stability in self-leveling mortars. Its main advantage, compared to CSA and CaO-based products, is the fact that for lower Portland cement replacement rates (10-20\%), ettringite formation is accelerated and controlled. It positively affects not only length change but also strength development and surface aspect. However, the mortar rheological behavior is negatively affected due to the high reactivity soon after mixing, which decreases fluidity and open time. Thus, setting retarders are needed to regulate reactivity.

Summary of solutions for dimensional stability: the main aspects and effects of the solutions for dimensional stability of self-leveling mortars are summarized in a simplified way in Table III. Although this table considers properties targeted for self-leveling mortar applied in screeds, it is important to consider that the same trends can be designed for other cementitious applications, as their properties may follow the same influences regarding binders, additives, or mechanical restriction agents. Additional comments for these solutions are: i) ternary system $\mathrm{OPC}-\mathrm{CAC}-\mathrm{CaSO}_{4}$ : in addition to the shrinkage compensation, early strength can also be achieved; however, the reactions to obtain early strength affect flow retention and reduce working time; this can be adjusted by setting regulator admixtures; ii) CSA-based expansive cement: although it has the shrinkage compensation and a fast setting time by ettringite formation, no early strength is achieved in the first hours; iii) CaO-based expander admixture: this admixture provides dimensional stability and increased strength over time; iv) shrinkage reducer (SRA): no significant effect on other properties of selfleveling mortar besides dimensional stability; decreases shrinkage but does not eliminate it; and v) polyethylene and steel fibers: although the fiber can affect negatively the rheological behavior of the mortar, flexural strength can be positively affected, as well as the residual strength after fracture; the dimensional control provided is limited.

\section{LITERATURE OVER TIME}

Themes such as self-leveling mortar, effects of shrinkage, and solutions to obtain dimensional stability are not subjects already consolidated through the years in the international literature, much less in Brazil. Through a quantitative survey in one of the main platforms (Web of Science) to access international scientific journals, it was possible to quantify the scientific publications over time related to these main themes (Fig. 31). The searched words were: self-leveling mortar and others (self-leveling underlayment, self-leveling screed, and self-leveling compound), shrinkage, and Portland cement-calcium aluminate-anhydrite (all three together referring to ternary system OPC-CAC-CaSO${ }_{4}$ ). The graphs show that the presence of the term self-leveling mortar is increasingly significant in technical articles over the years since 1999. The results for the combination of terms 'selfleveling mortar' and 'shrinkage' also grow steadily, despite the lower intensity, demonstrating that shrinkage is one of the main focuses when self-leveling mortar is studied due to its high importance. Therefore, the ternary system OPC-CAC$\mathrm{CaSO}_{4}$ has been investigated and published in correlation with shrinkage control in self-leveling applications since 2007. Its presence is also growing, showing to be a subject of interest and with advantages regarding dimensional stability.

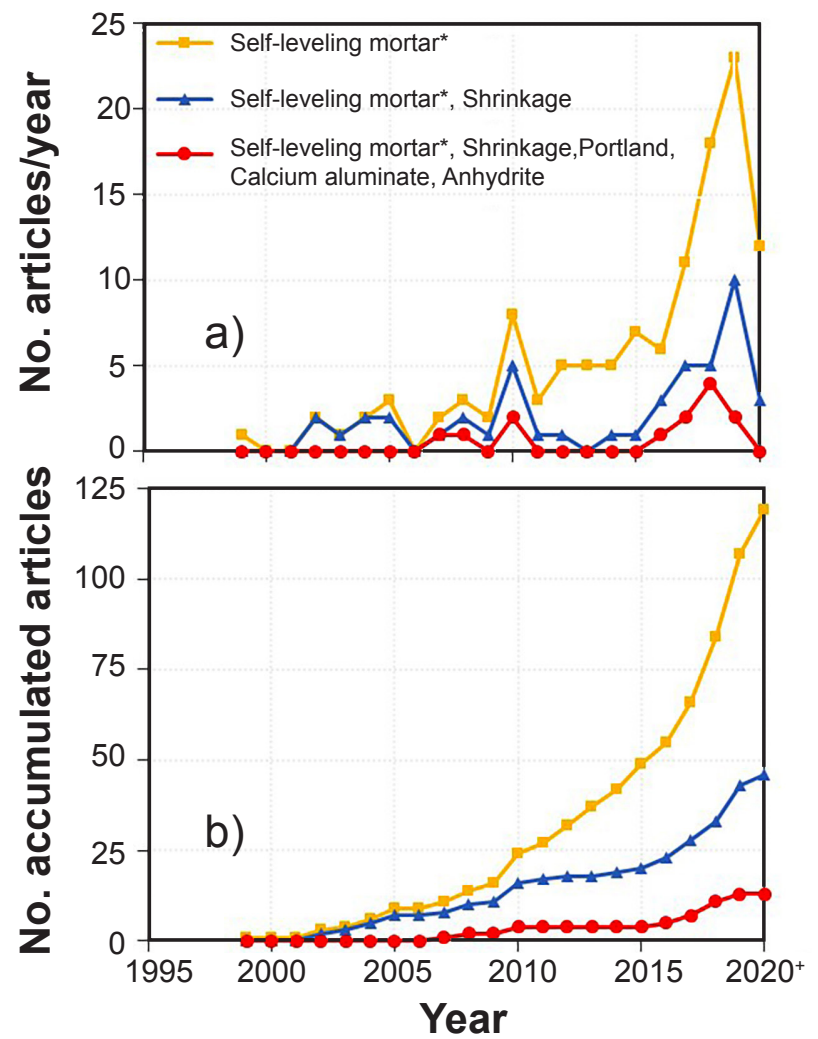

Figure 31: Number of articles published annually (a) and accumulated over time (b) for keyword combinations 'self-leveling mortar, shrinkage, and Portland-calcium aluminate-anhydrite' from the platform ScienceDirect through the article types 'review articles, research articles, conference abstracts, conference info, mini reviews, data articles, and product reviews' on May 19, 2020. Notes: * include self-leveling underlayment, self-leveling screed, and self-leveling compound; ${ }^{+}$does not consider the entire year 2020, only until May 19.

\section{FINAL REMARKS AND FUTURE PERSPECTIVES}

The current context of construction industrialization increasingly requests actions that ensure high productivity, mechanization of the processes, cost reduction, building quality improvement, safety and health at work, quick release of the area, and optimized quality and quantity of employees. In this scenario, the present literature review consolidates important topics related to the ternary system OPC-CAC-CaSO ${ }_{4}$ applied to self-leveling mortar. The main advantages of this system are related to shrinkage compensation mechanism based on ettringite formation and to the rapid strength development that favors the quality 
and the efficiency of screed application and regularization processes. While this solution is already disseminated in Europe and USA, in Brazil, the use of OPC-CAC-CaSO ${ }_{4}$ selfleveling mortars is still scarce compared to the conventional semi-dry cementitious screed. The lack of technical literature and disseminated knowledge for the application using local raw materials hinder the employment of this technology, an issue that is reflected by the inexistence of a Brazilian standardization. The paper has demonstrated that this product can be complex in all its stages, from raw materials selections and mix design, the reaction among binders types and dosages, to proper application control to ensure that all demands are met, such as self-fluidity without segregation and requirements of hardened properties focusing primarily on dimensional stability and strength development. The information collected and detailed in this single document, with quality bibliography on the mentioned subjects, is also useful for other types of applications (current or future) that demand properties control through the ternary system OPC-CAC-CaSO ${ }_{4}$, such as mortars for repair, precast formulations, and 3D printing of mortars and concretes. The properties of ternary system OPC-CAC-CaSO ${ }_{4}$ were compared with other solutions for dimensional stability, showing that it can be considered an efficient solution for self-leveling mortar or other application that has this request. However, this analysis was performed observing a general context and basically through international works. Therefore, it should be taken into consideration that studies have yet to be performed to verify the effectiveness of this solution for systems with its main component, Portland cement, from a Brazilian source. One relevant topic in this regard is the source of calcium sulfate (natural or artificial) used in Portland cement manufacturing and how it may affect the dimensional stability as well as other properties of the OPC-CAC-CaSO ${ }_{4}$ system.

\section{ACKNOWLEDGEMENTS}

The authors would like to gratefully acknowledge IMERYS - Refractory, Abrasives \& Construction team for all support provided and Prof. Maria Alba Cincotto (PoliUSP) for the technical discussions and kindly revising the paper. This research is part of the CEMtec project - National Institute on Advanced Eco-Efficient Cement Based Technologies, funded by $\mathrm{CNPq}$ - Conselho Nacional de Desenvolvimento Científico e Tecnológico - Brazil (Process 485340/2013-5) and FAPESP São Paulo Research Foundation (Process 14/50948-3 INCT/2014).

\section{REFERENCES}

[1] A.P. Rubin, "Industrialized self-levelling mortars for subfloor: analysis of physical and mechanical performance in comparison with dosed mortars", M.Eng. Dissert., Fed. Un. Rio Grande Sul, Porto Alegre (2015).

[2] V.M. Pereira, G. Camarini, Adv. Civ. Eng. 2018 (2018) 6378643.
[3] T. Egle, Rev. Téchne 164 (2010) 40.

[4] E.H. Nakakura, H.R.E. Bucher, II Brazil. Mortar Technol. Symp., Salvador (1997) 305.

[5] A. Rego, "Calcium aluminate cement technology: advantages and benefits in construction chemistry", ANAPRE, S. Paulo (2017).

[6] J. Gołaszewski, Constr. Build. Mater. 35 (2012) 586.

[7] A. De Gasparo, M. Herwegh, R. Zurbriggen, K. Scrivener, Cem. Concr. Res. 39 (2009) 313.

[8] K. Onishi, T.A. Bier, Cem. Concr. Res. 40 (2010) 1034.

[9] S. Zhang, X. Xu, S.A. Memon, Z. Dong, D. Li, H. Cui, Constr. Build. Mater. 167 (2018) 253.

[10] J.F. Georgin, J. Ambroise, J. Péra, J.M. Reynouard, Cem. Concr. Compos. 30 (2008) 769.

[11] C.O. Schaefer, "Valuation of an alternative source of calcium sulfate for the production of self-leveling mortars", Dr. Thesis, Fed. Un. Santa Catarina, Florianopolis (2013).

[12] L.S. Girotto, M.P. Barbosa, G.F. Maciel, IBRACON Struct. Mater. J. 7, 1 (2014) 24.

[13] S.H.L. da Silva, "Development of self-leveling mortar formulations for floors and evaluation of drying shrinkage", M.Eng. Diss., Fed. Un. Paraná, Curitiba (2016).

[14] A.A. de Melo Neto, "Influence of shrinkage reducing and compensators additives in mortars and pastes with activated slag cement", Dr. Thesis, Un. S. Paulo (2008).

[15] W. Chen, H.J.H. Brouwers, Constr. Build. Mater. 26 (2012) 670.

[16] P.P.F. Rodrigues, Industrial floors with compensated shrinkage concrete, J.J. Carol Ed., S. Paulo (2019).

[17] R. Kwasny-Echterhagen, L. Amathieu, F. Estienne, Int. Conf. Dry Mixes, St. Petersburg (2003).

[18] G. Cichinelli, Rev. Téchne 192 (2012) 288006.

[19] ASTM C1708/C1708M, "Test methods for self-leveling mortars containing hydraulic cements", ASTM Int. (2016).

[20] Peramin, "Self-leveling screeds", https://peramin.com, ac. 18/08/2019.

[21] Peramin, "Self-leveling underlayments", https:// peramin.com, ac. 18/08/2019.

[22] R.G. Pileggi, M.A. Cincotto, V.M. John, Rev. Ciên. Tecnol. Mater. Constr. Civil 3 (2006) 62.

[23] O. Esping, "Early age properties of self-compacting concrete: effects of fine aggregate and limestone filler", $\mathrm{PhD}$ Thesis, Chalmers Un. Technol., Göteborg (2007).

[24] T.A. Bier, F. Estienne, L. Amathieu, Int. Conf. Calcium Alumin. Cem., Edinburgh (2001).

[25] A. Rego, C. Alt, S. Favier, $6^{\text {th }}$ Latin Am. Drymix Mortar Conf., S. Paulo (2019).

[26] T. Opravil, P. Ptáček, F. Šoukal, J. Havlica, J. Brandštetr, J. Therm. Anal. Calorim. 111 (2013) 517.

[27] ACI Committee 223, "Guide for the use of shrinkage compensating concrete", Am. Concr. Inst. (2010).

[28] W. Li, J. Yu, S. Ma, Y. Hu, D. Ge, X. Shen, Ceram. Silikaty 62, 4 (2018) 364.

[29] J. Péra, J. Ambroise, Cem. Concr. Res. 34 (2004) 671.

[30] R. Trauchessec, J.-M. Mechling, A. Lecomte, A. Roux, B. Le Rolland, Cem. Concr. Compos. 56 (2015) 106.

[31] J.W. Bullard, H.M. Jennings, R.A. Livingston, A. 
Nonat, G.W. Scherer, J.S. Schweitzer, K.L. Scrivener, J.J. Thomas, Cem. Concr. Res. 41 (2011) 1208.

[32] L. Amathieu, Th.A. Bier, K.L. Scrivener, Int. Conf. Calcium Alumin. Cem., Edinburgh (2001).

[33] Z. Xiaowei, L. Chunxia, S. Junyi, Constr. Build. Mater. 112 (2016) 877.

[34] X. Zhang, Y. He, C. Lu, Z. Huang, Constr. Build. Mater. 157 (2017) 1065.

[35] D. Torréns-Martín, L. Fernández-Carrasco, M.T. Blanco-Varela, J. Therm. Anal. Calorim. 114 (2013) 799.

[36] C. Evju, S. Hansen, Cem. Concr. Res. 35 (2005) 2310.

[37] J. Bizzozero, "Hydration and dimensional stability of calcium aluminate cement based systems", Dr. Thesis, Swiss Fed. Inst. Technol. Lausanne (2014).

[38] L. Amathieu, B. Valdelièvre, F. Estienne, "Calcium aluminate cement: a polyvalent binder for various applications in the dry mortar industry", Neuilly-sur-Seine.

[39] T.A. Bier, L. Amathieu, CONCHEM Congr., Germany (1997).

[40] J.O. da Silva, Produto RT 68, "Perfil do cimento", J. Mendo Consult. (2009).

[41] S. Mohammed, O. Safiullah, Constr. Build. Mater. 164 (2018) 362.

[42] A.P. Kirchheim, V. Fernàndez-Altable, P.J.M. Monteiro, D.C.C. Dal Molin, I. Casanova, J. Mater. Sci. 44 (2009) 2038.

[43] K.L. Scrivener, A. Nonat, Cem. Concr. Res. 41 (2011) 651.

[44] K.L. Scrivener, P. Juilland, P.J.M. Monteiro, Cem. Concr. Res. 78 (2015) 38.

[45] K. Scrivener, A. Ouzia, P. Juilland, A. Kunhi Mohamed, Cem. Concr. Res. 124 (2019) 105823.

[46] B.B. Mariani, "Production of Portland clinker with low $\mathrm{CO}_{2}$ emissions from the incorporation of unreacted ore (MNR) from the production of $\mathrm{TiO}_{2}$ ", M.Eng. Diss., Fed. Un. Bahia, Salvador (2018).

[47] R. Skapa, "Optimum sulfate content of Portland cement", Masaryk Un., Brno (2009).

[48] "Basic Portland cement usage guide", ABCP, S. Paulo (2002).

[49] A.F. Bentivegna, J.H. Ideker, K.J. Folliard, Calcium Alumin. Proc. Int. Conf., Avignon (2014) 383.

[50] K. Ann, C.-G. Cho, Materials 7 (2014) 887.

[51] W.R.L. da Silva, H. Fryda, J.-N. Bousseau, P.-A. Andreani, T.J. Andersen, in Adv. Additive Manufact., Model. Syst. 3D Prototyp., M. Di Nicolantonio, E. Rossi, T. Alexander (Eds.), Springer Int., Cham (2020) 35.

[52] C. Stancu, N. Angelescu, M. Muntean, Calcium Alumin. Proc. Int. Conf., Avignon (2014) 364.

[53] K.M. Parker, J.H. Sharp, Trans. J. Br. Ceram. Soc. 81 (1982) 35.

[54] A. Nishikawa, Technology of monolithic refractories, Plibrico Japan, Tokyo (1984).

[55] C. Stabler, C. Breunig, F. Goetz-Neunhoeffer, J. Neubauer, H. Fryda, R. Kwasny-Echterhagen, Calcium Alumin. Proc. Int. Conf., Avignon (2014) 177.

[56] H.F.W. Taylor, Cement chemistry, $2^{\text {nd }}$ ed., T. Telford,
London (1997).

[57] B. Touzo, P.A. Andreani, Calcium Alumin. Proc. Int. Conf., Avignon (2014) 33.

[58] S. Kosmatka, M. Wilson, Design and control of concrete mixtures: the guide to applications, methods, and materials, $15^{\text {th }}$ ed., Portland Cem. Ass. (2011).

[59] K. Nahagawa, I. Terashima, K. Asaga, M. Daimon, Cem. Concr. Res. 20 (1990) 655.

[60] R. Yoshino, T. Higuchi, H. Udagawa, $12^{\text {th }}$ Int. Congr. Chem. Cem., Montreal (2007).

[61] S. Suárez, X. Roca, S. Gasso, J. Clean. Prod. 117 (2016) 150.

[62] M.A. Cincotto, V.M. John, in Civil Constr. Mater. Princ. Mater. Sci. Eng., IBRACON, S. Paulo (2017) 727.

[63] M.S. Bezerra, Techn. Rep. 34, "Perfil da gipsita", J. Mendo Consult. (2009).

[64] F.C. Holanda, H. Schmidt, V.A. Quarcioni, Cem. Concr. Compos. 83 (2017) 384.

[65] G. Azimi, V.G. Papangelakis, J.E. Dutrizac, Fluid Phase Equilib. 260, 2 (2007) 300.

[66] A. Rego, P. Evangelista, "Portland cement acceleration with calcium aluminate cement", S. Gonçalo (2016).

[67] J. Nehring, J. Neubauer, S. Berger, F. GoetzNeunhoeffer, Cem. Concr. Res. 107 (2018) 264.

[68] P. Gu, Y. Fu, J.J. Beaudoin, Cem. Concr. Res. 24 (1994) 682.

[69] P. Gu, J.J. Beaudoin, E.G. Quinn, R.E. Myers, Adv. Cem. Based Mater. 6 (1997) 53.

[70] L. Xu, P. Wang, G. Zhang, J. Therm. Anal. Calorim. 110 (2012) 725 .

[71] K. Watanabe, M. Shikawa, M. Wakamatsu, Taikabutsu Overseas 9, 1 (1989) 41.

[72] R.O.C. Romano, F.A. Cardoso, R.G. Pileggi, in "Concreto: ciência e tecnologia", IBRACON, S. Paulo (2011) 453.

[73] D. Feys, R. Verhoeven, G. De Schutter, Cem. Concr. Res. 38 (2008) 920.

[74] P.F.G. Banfill, in "Rheology reviews 2006", Br. Soc. Rheol. (2006) 61.

[75] M.S. de França, B. Cazacliu, F.A. Cardoso, R.G. Pileggi, Constr. Build. Mater. 223 (2019) 81.

[76] F.A. Cardoso, "Mix design method for rendering mortars based on particle size distribution and rheological behaviour", Dr. Thesis, Un. S. Paulo (2009).

[77] E.K. Kudo, F.A. Cardoso, R.G. Pileggi, Amb. Constr. 13 (2013) 125.

[78] F.A. Cardoso, R.G. Pileggi, "Rotational rheometry applied for the evaluation of mixing and rheological behavior of BASF-Germany self-leveling mortars with different combinations of admixtures", Un. S. Paulo (2007). [79] P.S. Shah, 50 ${ }^{\text {th }}$ Brazil. Concr. Congr., Salvador (2008).

[80] R. Pilar, R. Ferron, W. Repette, Rev. Matér. 23 (2018) e12150.

[81] T. Emoto, T.A. Bier, Cem. Concr. Res. 37 (2007) 647.

[82] S.B. Sun, J.W. Li, J.J. Li, L. Zhao, Appl. Mech. Mater.

863 (2017) 59.

[83] A. Qorllari, E. Qoku, T.A. Bier, T. Dilo, UBT Int. Conf., 
Un. Busin. Technol., Durres (2017).

[84] J.M. Lees, B. Gruffydd-Jones, C.J. Burgoyne, Constr. Build. Mater. 9 (1995) 413.

[85] A. Puri, G. Voicu, A. Badanoiu, Rev. Chim. 61, 8 (2010) 740.

[86] M.J.C. Viecili, D. Hastenpflug, R. Girardi, Rev. Matér. 23, 3 (2018) e 12172.

[87] J.-D. Lemay, M. Jolin, R. Gagné, Calcium Alumin. Proc. Int. Conf., Avignon (2014) 253.

[88] M.S.S. Ribeiro, Mater. Struct. 31 (1998) 400.

[89] C. Lobo, M.D. Cohen, Cem. Concr. Res. 21 (1991) 229.

[90] J. Kighelman, "Hydration and structure development of ternary binder system as used in self-levelling compounds",
PhD Thesis, Swiss Fed. Inst. Technol. Lausanne (2007). [91] D. Min, T. Mingshu, Cem. Concr. Res. 24 (1994) 119. [92] L. Xu, P. Wang, G. Zhang, Constr. Build. Mater. 31 (2012) 347.

[93] S.-J. Jang, J.-H. Kim, S.-W. Kim, W.-S. Park, H.-D. Yun, Sustainability 11, 5 (2019).

[94] M. Collepardi, R. Troli, M. Bressan, F. Liberatore, G. Sforza, Cem. Concr. Compos. 30 (2008) 887.

[95] P. Chaunsali, S. Lim, P. Mondal, D. Foutch, D. Richardson, Y. Tung, "Bridge decks: mitigation of cracking and increased durability", Rep. FHWA-ICT-13-023, Illinois Cent. Transport. (2013).

(Rec. 27/02/2020, Rev. 30/06/2020, Ac. 05/08/2020) 